\title{
MiR-212-3p Functions as a Tumor Suppressor Gene in Group 3 Medulloblastoma via Targeting Nuclear Factor I/B (NFIB)
}

\author{
Naveenkumar Perumal \\ University of Nebraska Medical Center, naveenkumar.perumal@unmc.edu \\ Ranjana K. Kanchan \\ University of Nebraska Medical Center, ranjana.kanchan@unmc.edu \\ David Doss \\ Creighton University School of Medicine \\ Noah Bastola \\ Washington University School of Medicine \\ Pranita Atri \\ University of Nebraska Medical Center, p.atri@unmc.edu \\ Tell us how you used this information in this short survey.

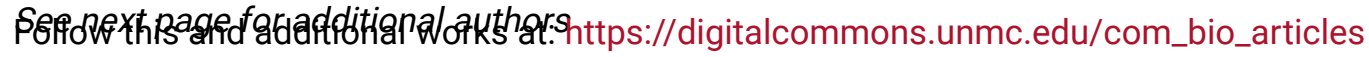 \\ Part of the Medical Biochemistry Commons, and the Medical Molecular Biology Commons
}

\section{Recommended Citation \\ Perumal, Naveenkumar; Kanchan, Ranjana K.; Doss, David; Bastola, Noah; Atri, Pranita; Venkata, Ramakanth C.; Thapa, Ishwor; Vengoji, Raghupathy; Maurya, Shailendra K.; Klinkebiel, David; Talmon, Geoffrey A.; Nasser, Mohd W.; Batra, Surinder K.; and Mahapatra, Sidharth, "MiR-212-3p Functions as a Tumor Suppressor Gene in Group 3 Medulloblastoma via Targeting Nuclear Factor I/B (NFIB)" (2021). Journal Articles: Biochemistry \& Molecular Biology. 147. \\ https://digitalcommons.unmc.edu/com_bio_articles/147}

This Article is brought to you for free and open access by the Biochemistry \& Molecular Biology at DigitalCommons@UNMC. It has been accepted for inclusion in Journal Articles: Biochemistry \& Molecular Biology by an authorized administrator of DigitalCommons@UNMC. For more information, please contact digitalcommons@unmc.edu. 


\section{Authors}

Naveenkumar Perumal, Ranjana K. Kanchan, David Doss, Noah Bastola, Pranita Atri, Ramakanth C. Venkata, Ishwor Thapa, Raghupathy Vengoji, Shailendra K. Maurya, David Klinkebiel, Geoffrey A. Talmon, Mohd W. Nasser, Surinder K. Batra, and Sidharth Mahapatra 


\title{
MiR-212-3p functions as a tumor suppressor Check for
updates gene in group 3 medulloblastoma via targeting nuclear factor I/B (NFIB)
}

\author{
Naveenkumar Perumal' ${ }^{1}$ Ranjana K. Kanchan' ${ }^{1}$, David Doss², Noah Bastola ${ }^{3}$, Pranita Atri ${ }^{1}$,
} Ramakanth Chirravuri-Venkata' ${ }^{1}$ Ishwor Thapa ${ }^{4}$, Raghupathy Vengoji', Shailendra K. Maurya' , David Klinkebiel ${ }^{1}$, Geoffrey A. Talmon ${ }^{5}$, Mohd W. Nasser ${ }^{1}$, Surinder K. Batra ${ }^{1}$ and Sidharth Mahapatra, ${ }^{1,6^{*}}$ (1)

\begin{abstract}
Haploinsufficiency of chromosome 17p and c-Myc amplification distinguish group 3 medulloblastomas which are associated with early metastasis, rapid recurrence, and swift mortality. Tumor suppressor genes on this locus have not been adequately characterized. We elucidated the role of miR-212-3p in the pathophysiology of group 3 tumors. First, we learned that miR-212-3p undergoes epigenetic silencing by histone modifications in group 3 tumors. Restoring its expression reduced cancer cell proliferation, migration, colony formation, and wound healing in vitro and attenuated tumor burden and improved survival in vivo. MiR-212-3p also triggered c-Myc destabilization and degradation, leading to elevated apoptosis. We then isolated an oncogenic target of miR-212-3p, i.e. NFIB, a nuclear transcription factor implicated in metastasis and recurrence in various cancers. Increased expression of NFIB was confirmed in group 3 tumors and associated with poor survival. NFIB silencing reduced cancer cell proliferation, migration, and invasion. Concurrently, reduced medullosphere formation and stem cell markers (Nanog, Oct4, Sox2, CD133) were noted. These results substantiate the tumor-suppressive role of miR-212-3p in group $3 \mathrm{MB}$ and identify a novel oncogenic target implicated in metastasis and tumor recurrence.
\end{abstract}

Keywords: 17p13.3, c-Myc, Group 3 medulloblastoma, miR-212-3p, Nuclear factor I/B

\section{Introduction}

Medulloblastoma $(\mathrm{MB})$, the most common malignant brain tumor of childhood, accounts for $20 \%$ of pediatric central nervous system (CNS) neoplasms with annual age-adjusted incidence ranging from 0.38 to 0.42 per 100,000 persons [32, 39]. Wingless-type (WNT), sonic hedgehog $(\mathrm{SHH})$, group 3 , and group 4 are the classic subgroups of MB with distinctive clinicopathologic and molecular features [37]. The most aggressive tumors fall into group 3 (non-SHH/WNT MB), which account for

*Correspondence: sidharth.mahapatra@unmc.edu

${ }^{6}$ Department of Pediatrics, University of Nebraska Medical Center, Omaha, NE 68198, USA

Full list of author information is available at the end of the article approximately $25-30 \%$ of all $\mathrm{MB}$ cases and belong to a high-risk subgroup punctuated by haploinsufficiency of $17 \mathrm{p}$ (20-50\% incidence), c-Myc amplification (15$20 \%$ incidence), and metastases close to or at diagnosis (30-40\%), all resulting in very poor prognosis with $<50 \%$ 5-year survivorship [3, 25, 38, 45]. Current treatment regimens involve surgical resection followed by a combination of craniospinal radiation and multi-agent chemotherapy, including vincristine, cisplatin, and either cyclophosphamide or lomustine [40, 41]. Recent studies have implicated MB tumor-initiating (stem) cells in evading chemotherapeutic regimens, facilitating recurrence $[15,31]$. Recurrence can further reduce 5 -year survival to $<10 \%[25,43]$. Thus, there is an urgent need to understand group $3 \mathrm{MB}$ pathobiology and key signaling 
pathways involved in disease progression and tumor recurrence to provide a more accurate risk-adapted targeted treatment approach that can mitigate the dismal survivorship of these patients.

Frequent cytogenetic events target the 17p13.3 locus in group $3 \mathrm{MB}$ and are associated with poor prognosis $[6,7,33]$. Along this locus are multiple tumor suppressor genes and microRNAs (miRNAs), short nucleotide noncoding RNAs capable of inhibiting expression of target genes by preventing translation or promoting degradation [2]. We recently reported the tumor-suppressive properties of miR-1253, which lies on the terminal end of this locus, in MB [24]. Similarly along this locus lies miR-212-3p, a tumor suppressor gene in various cancers, including lung cancer [19], hepatocellular carcinoma [5], prostate cancer [56], and glioblastoma [28]. In colorectal cancer [34] and nasopharyngeal carcinoma [20], miR212-3p targets MnSOD and Sox4, respectively, to prevent metastasis and invasion. In breast cancer, miR-212-3p regulates angiogenesis through Sp1 and VEGFA [27]. It can also sensitize cetuximab-resistant cells to growth inhibition in head and neck squamous cell carcinoma by targeting HBEGF [18]. Other oncogenic targets of miR212-3p include CTGF [5], Engrailed-2 [56], and SGK3 [28], which are involved in cancer cell proliferation, migration, and invasion.

To date, no studies have examined the role of miR212-3p in MB pathogenesis. Given its location on a highly afflicted chromosomal locus in high-risk MB, we hypothesized that miR-212-3p possesses tumor-suppressive properties. Here, we have focused on thoroughly elucidating the anti-neoplastic properties of miR-212-3p in group $3 \mathrm{MB}$ and revealed a new oncogenic target of this miR, Nuclear Factor I/B (NFIB).

\section{Methods}

Human tissue samples and molecular subgrouping of the MB tissues

Frozen and formalin-fixed paraffin-embedded (FFPE) samples of normal cerebellum (pediatric $=12$, adult $=5$ ) and pediatric $\mathrm{MB}$ specimens $(\mathrm{WNT}=1, \mathrm{SHH}=7$, group $3=10$, group $4=14$, unknown $=7$ ) were collected from the Children's Hospital and Medical Center and the University of Nebraska Medical Center, Omaha. Tumor samples were sub-classified into four subgroups using genome-wide DNA methylome analysis (Illumina Methylation EPIC $850 \mathrm{~K}$ bead arrays) as previously described [24]. Normal cerebellum specimens were obtained at autopsy. For expression profile of HDACs, EZH2, and NFIB, we cross-analyzed our local MB dataset (Kanchan et al., GSE148390) with publicly available MB datasets (Drusco et al., GSE62381; Roth et al., GSE3526; Gilbertson et al., GSE37418; Kool et al., GSE10327; and
Weishaupt et al., GSE124814) [9, 24, 52]. For KaplanMeier Survival Analysis, we used the R2 database (Cavalli et al., GSE85217) [3].

\section{Cell lines and cell culture}

All cell lines were authenticated using DNA methylation profiling (New York University) and short tandem repeat (STR) DNA profiling (UNMC). MB cell lines, i.e., D283, D341, D425, were maintained in DMEM with 10-20\% FBS and $100 \mu \mathrm{g} / \mathrm{mL}$ penicillin/streptomycin; HDMB03 cells were cultured in RPMI with $10 \%$ FBS and $100 \mu \mathrm{g} /$ $\mathrm{mL}$ penicillin/streptomycin. Normal Human Astrocytes (Lonza) were maintained using basal medium supplemented with growth factors. Cell lines were maintained in $95 \%$ humidity, $37^{\circ} \mathrm{C}, 5 \% \mathrm{CO}_{2}$.

\section{Reagents}

MirVana $^{\mathrm{TM}}$ miR-212-3p Mimic (Catalog: 4464066; Assay ID: MC10340) and scramble negative control (Catalog: 4464059) were purchased from ThermoFisher Scientific. Silencing RNA for NFIB and EZH2 (Silencer ${ }^{\mathrm{TM}}$ PreDesigned siRNA (Catalog: 4392420); Assay ID: s9495 and s4918, respectively) were obtained from ThermoFisher Scientific. Tet-On-miR-212-3p lentiviral vector and Tet3G (3rd generation) expression lentiviral vector (Vector ID:VB180123-1018bxq) were purchased from Vector Builder Inc. Detailed reagent sections can be found in the Additional file 1.

\section{MicroRNA quantification}

MiR-212-3p expression was quantified using TaqMan $^{\text {TM }}$ MicroRNA Reverse Transcription Kit and TaqMan ${ }^{\text {TM }}$ Advanced miRNA Assay (Applied Biosystems). Isolated total RNA was reverse transcribed using a specific stemloop primer for miR-212-3p (Catalog: 4427975, Assay ID: 000515) and RNA U6B (Catalog: 4427975, Assay ID: 001093). After One-step TaqMan RT-PCR, miR-212-3p was quantified and normalized to RNU6B using the delta-delta Ct method.

\section{DNA methylation profiling}

Genome-wide DNA methylome analysis was performed using the Illumina Methylation EPIC 850K bead arrays as previously described [36]. Genomic DNA was extracted from normal cerebellum and MB FFPE samples using RecoverAll $^{\mathrm{TM}}$ Total Nucleic Acid Isolation Kit (Invitrogen). Results are presented as percent methylation at each $\mathrm{CpG}$ measured.

\section{De-methylation studies}

HDMB03 cells $\left(3 \times 10^{5}\right.$ in 6 -well plates $)$ were treated with global de-methylating agent 5-AzaC (5 $\mu \mathrm{M})$ (5-Aza2-deoxycytidine; Sigma). Following 96 h of incubation, 
miR-212-3p expression was analyzed using TaqMan RTPCR and presented as relative fold expression compared to control.

\section{Chromatin immunoprecipitation assay}

The chromatin immunoprecipitation (ChIP) assay was performed with the Simplechip Enzymatic Chromatin IP kit (CST, Catalog: 9003). Briefly, the digested cross-linked chromatin $(10 \mu \mathrm{g})$ was subjected to immunoprecipitation with $5 \mu \mathrm{g}$ of anti-H3K27me3, anti-H3K4me3, antiH3K9me2, anti-H3K9Ac, or mouse/rabbit IgG control. Purified ChIP DNA was amplified using specific primers (Forward: 5'-GGAGTCCAGCTTCCTCTCCT-3'; and Reverse: 5'-GCTCCTGGGGGTCTTCAC-3') detecting the $\mathrm{CpG}$-enriched upstream promoter region of human miR-212-3p. Results are presented as relative enrichment normalized to respective input samples.

\section{Stable inducible miR-212-3p expression system}

Stable HDMB03 cells expressing inducible miR-212 with luciferase reporter were generated using Tet-On Inducible lentiviral vector and Tet3G (3rd generation) lentiviral vector (VectorBuilder Inc.). Briefly, lentiviral particles containing Tet3G vector were transduced with group $3 \mathrm{MB}$ cell line (HDMB03 cells). Following hygromycin antibiotic selection $(100 \mu \mathrm{g} / \mathrm{ml})$, stable HDMB03 cells expressing Tet3G were transduced with lentiviral particles containing inducible miR-212 expression system. The pure population of cells expressing inducible miR212 and luciferase reporter was double-selected using puromycin selection $(1 \mu \mathrm{g} / \mathrm{ml})$ and mCherry positive cell population sorting (flow cytometry).

\section{MiR-212-3p expression restoration}

Group $3 \mathrm{MB}$ cells $\left(3 \times 10^{5}\right)$ were seeded overnight and subsequently serum-starved for $4 \mathrm{~h}$ prior to transient transfection using Lipofectamine 2000 (Invitrogen) for $6 \mathrm{~h}$ in serum-free media with miR-212-3p mimic (25 nM and $50 \mathrm{nM})$ or scramble control $(25 \mathrm{nM})$. Following incubation, fresh complete medium was added. For stable induction, HDMB03 cells were treated with or without Doxycycline (Dox, $500 \mathrm{ng} / \mathrm{ml}$ ) in complete medium and incubated at $37^{\circ} \mathrm{C}, 5 \% \mathrm{CO}_{2}$.

\section{Cell proliferation assay}

MTT [3-(4, 5-dimethylthiazol-2-yl)-2, 5-diphenyl- 2H-tetrazolium bromide] and WST-1 [(4- [3-(4-Iodophenyl)-2-(4-nitro-phenyl)-2H-5tetrazolio]-1,3-benzene sulfonate)] assays were used to determine cell viability in group $3 \mathrm{MB}$ cells. After transfection/Dox treatment, assays were performed at 24-96 h; absorbances were measured using a microplate reader at $570 \mathrm{~nm}$ (MTT assay) and $440 \mathrm{~nm}$ (WST-1 assay); data were analyzed using the SOFTMAX PRO software (Molecular Devices Corp.).

\section{Colony formation assay}

After transfection/Dox treatment, $\mathrm{MB}$ cells $\left(1 \times 10^{3}\right.$ cells/well) were reseeded in 6-well plates and grown for 7-10 days in a humidified atmosphere (95\% humidity) at $37{ }^{\circ} \mathrm{C}$ and $5 \% \mathrm{CO}_{2}$. Cells were washed, fixed with $2.5 \%$ methanol and stained with $0.5 \%$ crystal violet. Cell staining was dissolved using $10 \%$ acetic acid and quantified by measuring the absorbance at $590 \mathrm{~nm}$.

\section{Cell migration and invasion assay}

For transwell migration/invasion assay, transfected/Dox treated stable cells $\left(5 \times 10^{5}\right.$ cells $)$ in serum-free media were seeded in the upper chamber of an insert $(8 \mathrm{~mm}$ pore size; BD Bioscience) coated with Fibronectin (BD Bioscience) or Matrigel (Invasion Chamber Matrigel Matrix) followed by addition of a chemoattractant (10\% FBS in complete media) to the lower chamber. After overnight incubation (16 h), cells that migrated/invaded into the lower chamber were stained using Diff-Quik Stain Set (Siemens Healthcare Diagnostics, Inc.); images were captured using an EVOS FL Auto Imaging System (Life Technologies). Results were quantitated by taking an average cell count, measuring cell numbers from fourfield/images/well $(10 \times$ magnification $)$.

\section{Wound healing assay}

After transient transfection, cells $\left(5 \times 10^{5}\right.$ cells/well $)$ were plated in a 6 -well plate, and upon reaching $80 \%$ confluence, a vertical scratch was made using a $10 \mu \mathrm{L}$ pipette tip. For stable cells, $3 \times 10^{4}$ cells/well were seeded in a culture-insert (ibidi culture-insert 2 well), and after overnight incubation the culture-insert was removed and washed with PBS to remove non-adherent cells. Fresh growth medium (with and without Dox $(500 \mathrm{ng} / \mathrm{ml})$ ) supplemented with $5 \%$ serum was added to the plates. The wound closure area was photographed at denoted time intervals using an EVOS FL Auto Imaging System (Life Technologies). Quantitative measurements (\% wound closure) were determined by measuring three fields per well.

\section{Apoptosis and cell cycle analysis}

Annexin- $\mathrm{V} / \mathrm{Cy}^{\mathrm{TM}} 5$ (BD Biosciences) and propidium iodide (PI) (Roche Diagnostics) were used to measure apoptosis and cell cycle profile as previously described [24]. Briefly, miR-212-3p mimic or scramble control transfected cells were incubated for $96 \mathrm{~h}$. Following incubation, cells were washed and resuspended in calcium-binding buffer consisting of Annexin- $\mathrm{V} / \mathrm{Cy}^{\mathrm{TM}} 5$ and PI (apoptosis assay) or fixed with $70 \%$ ethanol and stained with PI (cell cycle 
analysis). Stained cells were analyzed using a FACS Canto $^{\mathrm{TM}}$ Flow cytometer (BD Bioscience).

\section{Western blotting}

Protein lysates (30 $\mu \mathrm{g} / \mathrm{lane}$ ) were separated on $10 \%$ SDSPAGE gels and transferred to PVDF membrane. Following blocking, target proteins were detected by probing overnight at $4^{\circ} \mathrm{C}$ with antibodies against: NFIB, Bin1 and p19 $9^{\mathrm{ARF}}$ (Abcam); PARP, cleaved PARP, cleaved caspase-3, caspase-3, cyclin D1, CDK4, CDK6, p-Akt-ser473, $\beta$-catenin, and CD133 (Cell Signaling Technologies); and total Akt, p-Erk and ERK (Santa Cruz Biotechnology). Then, membranes were washed and incubated with anti-mouse/rabbit IgG secondary antibody (Invitrogen) conjugated with horseradish peroxidase (HRP) at room temperature. Specific proteins were visualized using an enhanced chemiluminescence detection reagent (Pierce; ThermoFisher Scientific, Inc.).

\section{MiR-212 target prediction}

MiRNA target prediction databases, i.e., Targetscan (http://www.targetscan.org) and mirDIP (http://ophid. utoronto.ca/mirDIP/) were used to determine the putative targets of miR-212-3p. Genes that were downregulated upon miR-212-3p restoration in HDMB03 (RNA sequencing analysis) were compared against them. Targets were chosen based on $\log _{2}$ fold change $<-1$ and $p<0.05$, yielding 37 common gene targets for miR-212-3p.

\section{Dual-luciferase reporter assay}

Primers for $3^{\prime}$ UTR-NFIB (Forward: 5'-GCTTGCTAG CTACACACCAGGGT-3'; and Reverse: 5'-TAGCAG TATAGGCTGGATA- $3^{\prime}$ ) were designed using NCBIPrimer-BLAST tool (https://www.ncbi.nlm.nih.gov/ tools/primer-blast/) and purchased from Eurofins. Following PCR amplification of NFIB ( $\left.3^{\prime} \mathrm{UTR}\right)$, mutations were created within the seed sequence of NFIB. The resulting 3'UTR-Wild and 3'UTR-Mutant genes were inserted into the XbaI restriction site of pGL3-control vector (Promega) expressing firefly luciferase. Dualluciferase reporter assay was performed on $\mathrm{HDMB03}$ cells $\left(3 \times 10^{5}\right.$ cells/well $)$ seeded in 12 -well plates. Following overnight incubation, cells were co-transfected with 3'UTR-wild-pGL3/3'UTR-Mutant-pGL3 plasmid, pRL-TK plasmid (Promega) expressing Renilla luciferase (internal control), and miR-212-3p mimic/scramble control for $48 \mathrm{~h}$. Luciferase activity was then measured using the Dual-Luciferase Reporter Assay System (Promega) with a Luminometer (Biotek). Results are presented as Luciferase activity (\%), where firefly luciferase activity was normalized to Renilla luciferase activity (internal control) for each transfected sample.

\section{Immunohistochemistry}

Unstained tissue slides $(3 \mu \mathrm{m})$ were deparaffinized in xylene, rehydrated in a series of alcohol dilutions, and heated in citrate buffer ( $\mathrm{pH}$ 6.2) for 20 min. Following antigen retrieval, slides were incubated with blocking buffer (Horse serum, Vector Labs) for $60 \mathrm{~min}$ at room temperature. Subsequently, anti-NFIB (1:200), anti-cMyc (1:200), anti-Ki-67 (1:200), or anti-Cleaved Caspase 3 (1:200) primary antibody was added and incubated overnight at $4{ }^{\circ} \mathrm{C}$. After PBS wash, slides were incubated with secondary antibody (goat anti-rabbit/mouse conjugated with horseradish peroxidase) for $60 \mathrm{~min}$ at room temperature. Detection was performed with DAB Peroxidase Substrate Kit (Vector Labs) followed by counterstaining with hematoxylin. Sections were visualized under EVOS FL Auto Imaging System (Life Technologies). Then the tissues were scored according to the intensity of the dye color and the number of positive cells. The method for IHC score was as follows: 0, negative; $1,<25 \%$ positive tumor cells; $2,25-50 \%$ positive tumor cells; $3,50 \%-75 \%$ positive tumor cells; and $4,>75 \%$ positive tumor cells. Dye intensity was graded as 0 (no color), 1 (light yellow), 2 (light brown), or 3 (brown). Composite scores were derived from product of staining intensity and \% positive cells $(0-12)$.

\section{Sphere formation assay}

For primary and secondary spheres, HDMB03 cells $\left(4 \times 10^{5}\right.$ cells/well $)$ were seeded in Ultra-Low Attachment 6-well plates (Corning ${ }^{\mathrm{TM}}$ Costar $^{\mathrm{TM}}$ Microplates). Cells were maintained in stem cell media (DMEM/F12, 2\% B27, $20 \mathrm{ng} / \mathrm{mL}$ bFGF, $20 \mathrm{ng} / \mathrm{mL}$ EGF, $40 \mathrm{U} / \mathrm{ml}$ penicillin, and $40 \mu \mathrm{g} / \mathrm{ml}$ streptomycin), and incubated for 10 days at $37{ }^{\circ} \mathrm{C}, 5 \% \mathrm{CO}_{2}$. Following incubation, primary spheres were dissociated into single cell suspension, reseeded, and allowed to grow for another 10 days to form secondary spheres. Spheres having diameter larger than $50 \mu \mathrm{m}$ were counted.

\section{Orthotopic medulloblastoma mouse model}

All experimental animal procedures were approved by the Institutional Animal Care and Use Committee (IACUC). Briefly, four to six-week-old NSG (NOD-scid Il2rgnull) mice were anesthetized using ketamine and xylazine (i.p.) and transferred to a stereotactic frame (Stoelting Co, IL, USA). Hamilton syringe (26-gauge needle) with stable Tet-on miR-212 inducible HDMB03 cells $\left(1.0 \times 10^{5}\right.$ cells $/ 5 \mu \mathrm{l}$ of PBS $)$ was implanted into the cerebellum (2-mm lateral and 2-mm posterior to lambda, and $2.7-\mathrm{mm}$ deep from the surface of the skull), with a speed of $1 \mu \mathrm{l} / \mathrm{min}$. Needle was removed after $5 \mathrm{~min}$. After surgery, tumor growth, based on total photon flux, was measured using an IVIS Spectrum imaging system 
(Caliper life sciences; PerkinElmer, MA, USA). Based on tumor size, mice were randomized into two groups (i) control and (ii) DOX treatment group; doxycycline (2 mg daily through oral gavage) induced expression of miR-212-3p. Tumor growth was monitored using an IVIS Spectrum imaging system. On appearance of first neurological symptoms (as per IACUC guidelines), animals were euthanized. Brains were fixed for analysis.

\section{Statistical analysis}

All experiments were conducted in triplicate. Values are presented as mean \pm SD. Statistical analyses were performed using Prism 7.0b (GraphPad Software). For data normalization, control group was set at " 1 " and experimental groups were represented as fold-change compared to control with error bars reflecting deviation from mean triplicate measurements; statistical analyses were conducted prior to normalization. Differences between groups were compared using a two-tailed, unpaired Student's t-test, Mann-Whitney U test or one-way analysis of variance followed by a least significant difference post hoc test. Statistical significance was established at $" p<0.05, * * p<0.01$, and ${ }^{* * * *} p<0.001$.

\section{Results}

\section{MiR-212-3p expression is epigenetically silenced} by histone modifications in group $3 \mathrm{MB}$

Group 3 tumors belong to a high-risk subgroup punctuated by haploinsufficiency of $17 \mathrm{p}$ (20-50\% incidence), c-Myc amplification (15-20\% incidence), and metastases proximate to diagnosis $(30-40 \%)$, all resulting in $<50 \%$ 5-year survivorship [3, 25, 38, 45]. Our local MB cohort recapitulated these distinguishing findings in group 3 tumors, with a very high frequency of haploinsufficiency of $17 \mathrm{p}$ (90\%), c-Myc amplification (40\%), metastasis proximate to diagnosis (30\%), and low 5 -year overall survival (40\%), and was comparable to a larger MB dataset [3] (Additional file 2: Fig. S1A(i) and (ii)).

To explore the regulation of miR-212-3p in MB, we first conducted an in silico expression analysis of miR-212-3p in CSF samples of patients with $\mathrm{MB} \quad(\mathrm{NC}=14$ vs. $\mathrm{MB}=15 ;$ GSE62381), revealing reduced expression compared to normal (Fig. 1A (i)). Subsequent expression examination in our local pediatric $\mathrm{MB}$ cohort (GSE148390) revealed specific downregulation in group $3(\mathrm{n}=9)$ and group $4(\mathrm{n}=13)$ MB tumors (Fig. 1A (ii)). We cross validated these results using RT-PCR, noting near-abrogation of expression of miR-212-3p in group $3 \mathrm{MB}(\mathrm{n}=10)$ and group $4 \mathrm{MB}$ samples $(\mathrm{n}=12)$ compared to pediatric cerebellum $(n=10)$ (Fig. 1B). In vitro, we recapitulated these findings in a panel of MB cell lines with characteristic high-risk features, including i17q and c-Myc amplification (group 3 MB-D341, D425, HDMB03; group 3/4 MB-D283). These were in stark contrast to normal human astrocytes (NHA) and an $\mathrm{SHH}$ MB-type cell line, i.e. Daoy, with high expression of miR212-3p (Fig. 1C). These results substantiated a decreasedto-absent expression of miR-212-3p specific to group 3 and $4 \mathrm{MB}$ tumors and cell lines. We thus chose to focus the rest of our study on group 3 tumors.

To elucidate a mechanism for expression silencing, we studied epigenetic mechanisms, i.e. hypermethylation vs. histone modification. We initially performed DNA methylation profiling in our group $3 \mathrm{MB}$ patient samples $(n=6)$ but found no perturbation to the methylation of the miR-212-3p promoter region when compared to normal pediatric cerebellum $(n=4)$. In vitro, these findings were supported by a lack of expression restoration in HDMB03 cells treated with the global demethylating agent, 5-AzaC (5 $\mu \mathrm{M}, 96$ h) (Additional file 2: Fig. S1B).

Several studies have linked aberrant methylation and acetylation of key histones involved in chromatin structure, including H3K4 and H3K27, with enhanced disease aggressiveness mainly in group 3 and group 4 tumors [10, 22]. Moreover, studies targeting histone deacetylases (HDACs) have revealed growth inhibition of MYC-driven medulloblastomas [11, 12, 42]. Thus, we shifted our focus to histone modification-mediated epigenetic regulation. Our initial in silico analysis of HDAC expression revealed high expression of $\operatorname{HDAC} 1,3,5,9$,

(See figure on next page.)

Fig. 1 Expression and epigenetic regulation of miR-212-3p in group 3 MB tumors. A MiR-212 expression analysis by RNA Sequencing using (i) a publicly available MB dataset (NC $n=14 ; M B n=15$; Drusco et al., GSE62381) and (ii) a local MB cohort (adult NC $n=4$; pediatric NC $n=10$; SHH $n=5$; group $3 \mathrm{MB} n=9$; group $4 \mathrm{MB} n=13$; Kanchan et al., GSE148390). B Results validated in local MB cohort by RT-PCR (NC $n=10 ; \mathrm{G} 3 \mathrm{MB}$ $\mathrm{n}=10$; G4MB $n=12$ ). C RT-PCR analysis of miR-212 expression in classic MB cell lines (group 3: D341, D425, HDMB03; group 3/4: D283; SHH: Daoy) compared to normal human astrocytes (NHA). D In silico expression of HDACs and EZH2 to investigate epigenetic modulation of miR-212 (NC $\mathrm{n}=10$; group $3 \mathrm{MB} \mathrm{n}=7$; Kanchan et al., GSE148390). E ChIP-qRT-PCR analysis in group $3 \mathrm{MB}$ cells with deregulated histone modifications in the promoter region of miR-212-3p. ChIP grade histone mark antibodies to H3K27me3, H3K9me2 and H3K9Ac used; IgG antibody as negative control; Daoy cells with high intrinsic miR-212-3p expression served as an additional control. F MiR-212-3p expression restoration after treatment with pan-HDAC inhibitors (TSA, 100 nM; Belinostat, 1 MM; and Vorinostat, $1 \mu \mathrm{M}$ ) and with siRNA-EZH2 (20 nM) in HDMB03 cells. Increase in acetylated a-tubulin levels demonstrated pan-HDAC inhibitor activity in $\mathrm{HDMBO3}$ cells. $\beta$-actin served as an internal control. Data presented as mean \pm SD from experiments done in triplicate and analyzed using Mann-Whitney $U$ test $(\mathbf{A}$ and $\mathbf{D})$ or Student's t-test $(\mathbf{B}, \mathbf{C}, \mathbf{E}$ and $\mathbf{F}) ;{ }^{*} p<0.05,{ }^{* *} p<0.01$, ${ }^{* * *} p<0.001$. NC, normal cerebellum; MB, medulloblastoma; G3MB, group 3 medulloblastoma; G4MB, group 4 medulloblastoma 


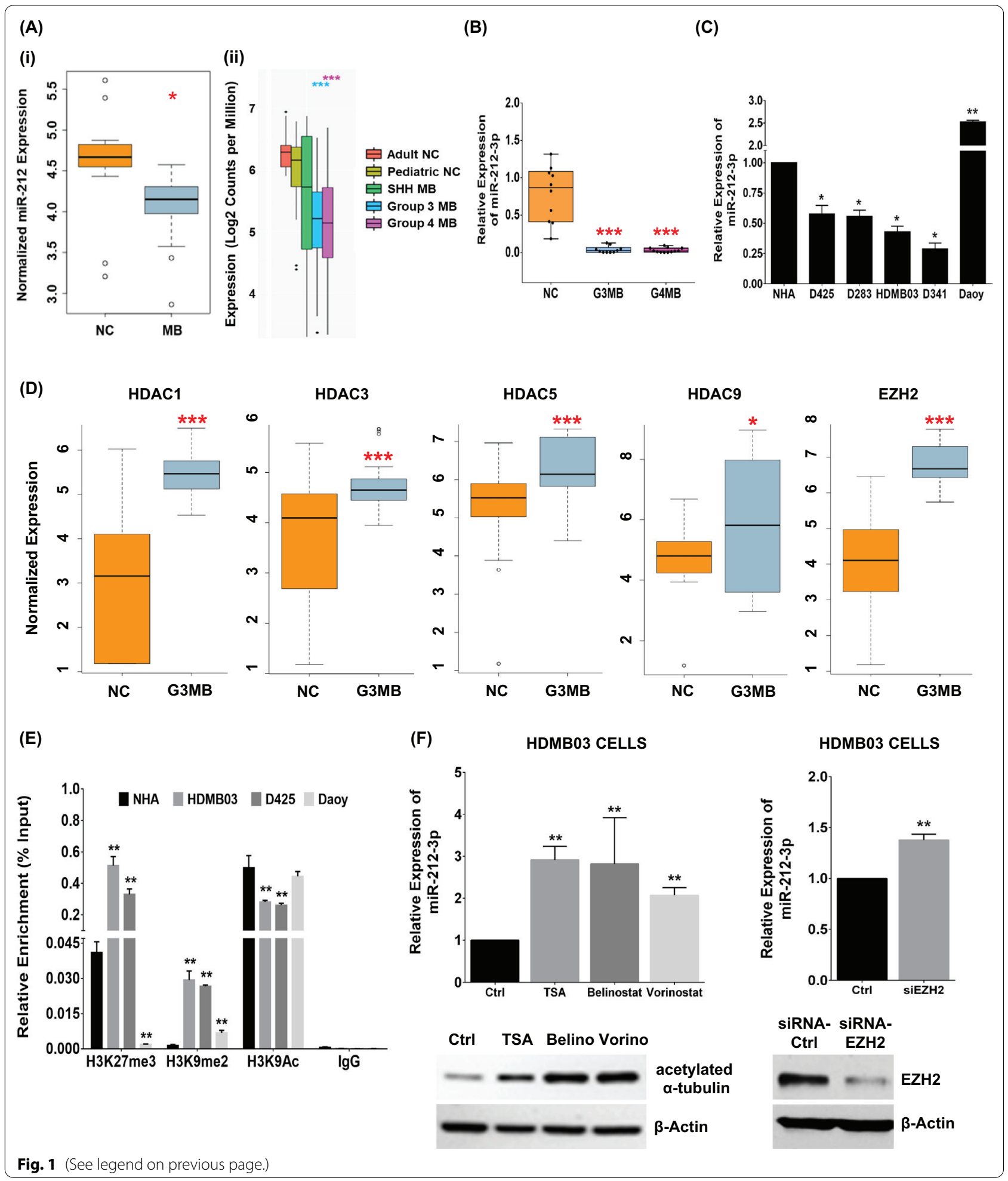

and EZH2 in both our local cohort (group $3 \mathrm{MB} \mathrm{n}=7$; GSE148390) and in a larger group $3 \mathrm{MB}$ cohort (group $3 \mathrm{MB} \mathrm{n}=233$; GSE124814) when compared to normal cerebellum $(n=10$ and $n=291$, respectively) (Fig. 1D and Additional file 2: Fig. S1C). To confirm a specific pattern of histone modification in the predicted miR-212-3p transcription start-site (TSS) in group 3 cells, histone mark patterns of group $3 \mathrm{MB}$ cell lines (HDMB03 and 
D425) were compared with normal human astrocytes (NHA) and an SHH MB cell line (Daoy). CHIP-qRT-PCR analysis revealed important differences in the methylation status of H3K27 and H3K9 and in the acetylation status of H3K9 in group $3 \mathrm{MB}$ cell lines compared to NHA and Daoy cells (Fig. 1E). Specifically, HDMB03 and D425 cells, with baseline reduced miR-212-3p expression, showed enriched methylated H3K27 and H3K9, with a concomitant decrease in acetylated H3K9, compared to NHA. In contrast, Daoy cells, with high intrinsic miR-212-3p expression, were hypomethylated at H3K27 and showed no change to the acetylation pattern of $\mathrm{H} 3 \mathrm{~K} 9$ compared to NHA. Consequently, treatment of HDMB03 and D425 cell lines with pan-HDAC inhibitors (TSA, $100 \mathrm{nM}$; Belinostat, $1 \mu \mathrm{M}$; Vorinostat, $1 \mu \mathrm{M}$ ) substantially increased miR-212-3p expression compared to vehicle control (Fig. 1F and Additional file 2: Fig. S1D). Silencing EZH2 expression (siRNA-EZH2, $20 \mathrm{nM}$ ) accomplished the same (Fig. 1F). Together, these findings strongly implicated a unique pattern of histone modification as a silencing mechanism for miR-212-3p in group $3 \mathrm{MB}$ tumors.

MiR-212-3p expression restoration inhibits group 3 MB cell growth and proliferation

To highlight the tumor-suppressive properties of miR212-3p in group $3 \mathrm{MB}$, we employed two methods to restore miR-212-3p expression, i.e. by transient transfection with miR-212-3p mimic or by Dox-inducible stable expression in group $3 \mathrm{MB}$ cell lines. With successful miR-212-3p expression restoration (Fig. 2A), cancer cell growth and proliferation were significantly impacted in a time- and dose-dependent manner (Fig. 2B). Similarly, colony formation, transwell migration, and wound closure assays all recapitulated this anti-neoplastic phenotype with reduced colonies, cellular migration, and wound closure, respectively (Fig. 2C-E). Although overexpressing miR-212-3p in Daoy cells decreased cell proliferation and colony formation, a dose- and timedependent effect was absent. Instead, growth inhibitory effects seemed to plateau within $24 \mathrm{~h}$ and with a $25 \mathrm{nM}$ concentration of miR-212-3p, suggesting that SHH cell lines do not experience the same growth inhibition as group 3 cell lines do (Additional file 3: Fig. S2A-C). These data provided compelling in vitro evidence for the tumor-suppressive properties of miR-212-3p, expressly in group $3 \mathrm{MB}$.

MiR-212-3p induces cell cycle arrest and destabilizes c-Myc to favor apoptosis in group $3 \mathrm{MB}$

Myc amplification is a cardinal high-risk feature of group $3 \mathrm{MB}$, and its phosphorylation status influences downstream tumor phenotype [43, 44]. More specifically,
c-Myc phosphorylated at serine 62 increases stability leading to tumor aggressiveness, while phosphorylation at threonine 58 destabilizes the protein, leading to ubiquitin-mediated degradation and subsequent cellular apoptosis [14, 23]. Transient transfection of HDMB03 cells with miR-212-3p resulted not only in a reduction in total c-Myc protein but also a concomitant increase in the ratio of phosphorylated T58 to phosphorylated S62 (Fig. 3A). Concurrently, the active upstream kinases responsible for $\mathrm{c}-\mathrm{Myc}$ stabilization via phosphorylation at S62, i.e. p-Erk and p-Akt [46], were both significantly decreased in these cells (Fig. 3A). In miR-212-3p stablyexpressing HDMB03 cells, c-Myc expression was almost completely abrogated, with consequent reductions in both phosphorylated species of c-Myc. As prior, p-AKT and p-ERK were also significantly reduced. Together, these data purported a c-Myc deregulatory function for miR-212-3p. Of note, in gastric cancer, c-Myc has been revealed as a direct target of miR-212 [55].

We then focused on progression through the cell cycle, given the destabilization of c-Myc and a reduced proliferative phenotype noted in the presence of miR-212-3p. Not surprisingly, we revealed arrest in transientlytransfected miR-212-3p mimic-treated cells (25 $\mathrm{nM}$ and $50 \mathrm{nM}$ ) at the $\mathrm{G}_{0} / \mathrm{G}_{1}$ phase of the cell cycle in HDMB03 cells (Fig. 3B). We confirmed the phase of arrest using Western blotting, which showed decreased expression of the complementary checkpoint markers, CDK4, CDK6, and cyclin D1 (Fig. 3A and C). In support, hierarchical clustering and pathways analysis revealed that miR212-3p expression restoration led to the enrichment of gene clusters $(4,5,8)$ involved in the regulation of cell cycle phase (Additional file 4: Fig. S3A and B, and Additional file 5: Table S1).

We concluded our study of the anti-neoplastic properties of miR-212-3p by analyzing its effect on cancer cell apoptosis. We first examined the expression of c-Myc binding partners that signal for apoptosis, i.e. Bin-1 and $\mathrm{p} 19^{\mathrm{ARF}}$, along with various pro-apoptotic proteins. MiR-212-3p restoration in HDMB03 cells significantly increased expression of Bin-1 and p $19^{\mathrm{ARF}}$ concurrent with rises in cleaved PARP and cleaved caspase 3 (Fig. 3D). These results were validated using Annexin V-cy5/PI staining, demonstrating a two- and threefold increase in late and early apoptosis, respectively, compared to control (Fig. 3E).

Taken together, our results identified an apoptotic mechanism for miR-212-3p, either by altering c-Myc phosphorylation states to destabilize c-Myc, by reducing the total c-Myc expression, and/or by increasing the expression of its pro-apoptotic binding partners. In parallel, miR-212-3p played a role in cell cycle arrest at the $\mathrm{G}_{0} / \mathrm{G}_{1}$ phase. 


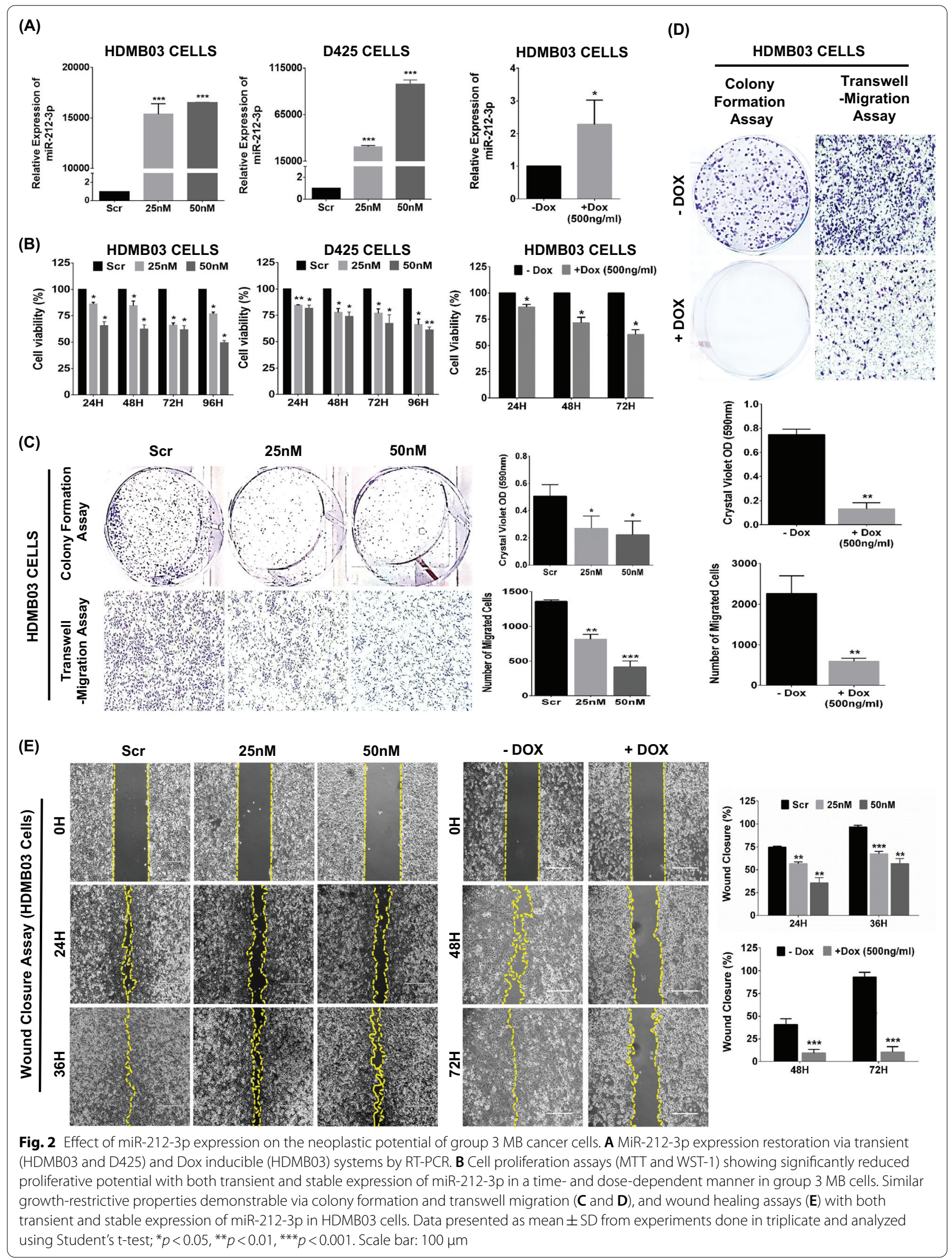


NFIB is a downstream target of miR-212-3p

To identify oncogenic targets of miR-212-3p, we started with the targets that are common to miRNA target prediction databases (TargetScan and mirDIP) and that are significantly downregulated $\left(\log _{2}\right.$ fold change $<-1.0$, $p<0.05)$ by miR-212-3p expression restoration in HDMB03 cells (Fig. 4A). This comparison revealed 37 putative targets whose expression and associated pathways were studied in two group $3 \mathrm{MB}$ patient cohorts (Fig. 4B (i) and (ii), and Additional file 6: Fig. S4A and B). Out of the 37 common targets, fourteen were upregulated in group $3 \mathrm{MB}$ (summarized in Additional file 7: Table S2). NFIB was chosen for further study based on the following characteristics that bestow a high likelihood of oncogenic potential in group $3 \mathrm{MB}$ : (i) there are two conserved binding sites for miR-212-3p on the $3^{\prime} U T R$ of NFIB mRNA (TargetScan); (ii) expression of NFIB was significantly increased across multiple $M B$ datasets (Fig. 4C); (iii) and significantly elevated across $\mathrm{MB}$ subgroups (Fig. 4D and Additional file 6: Fig. S4C); (iv) Kaplan-Meier Survival Analysis showed poor survival in high-expressing patients (Cavalli et al., GSE85217, via R2 database) [3] (Fig. 4E); (v) high expression was shown in a panel of group $3 \mathrm{MB}$ cell lines (HDMB03, D425, and D341) compared to NHA (Fig. 4F); and (vi) immunohistochemical staining of NFIB in group 3 MB tissues $(n=9)$ revealed intense nuclear staining when compared to normal cerebellum $(n=8)$ (Fig. 4G). We further validated this target by the dual-luciferase assay (Fig. $4 \mathrm{H}$ ) and showed significant attrition in miR-212-3p mimic treated HDMB03 cells at the transcription (Fig. 4I) and translation levels (Fig. 4J). In this manner, we identified NFIB as an oncogenic target of miR-212-3p.

\section{NFIB possesses oncogenic potential in group $3 \mathrm{MB}$ cancer cells}

Nuclear Factor I/B (NFIB) belongs to the nuclear factor I (NFI) family of transcription and replication proteins that recognize palindromic sequences on various promoters capable of activating transcription and replication throughout organ development [16, 49]. An oncogenic role for NFIB has been shown in triple-negative breast cancer (TNBC), small cell lung cancer (SCLC), colorectal and gastric cancers, and melanoma by enhancing tumor growth, epithelial-mesenchymal transition (EMT), migration, and invasion [13, 29, 30, 47, 53].

With this prior evidence, we elucidated the oncogenic role of NFIB in group $3 \mathrm{MB}$ cancer cells by studying the effect of silencing expression on proliferation, transwellmigration, and invasion. Silencing NFIB in HDMB03 cells transiently resulted in a significant reduction in cell proliferation up to $48 \mathrm{~h}$ (Fig. 5A). Transwell migration and invasion assays demonstrated similar reductions in cell migration and invasion (Fig. 5B).

Mechanistically, NFIB overexpression has been shown to increase chromatin accessibility, promote the expression of pro-metastatic genes, and drive metastasis in SCLC tumors [8, 47, 54]. Studies in SCLC have also revealed NFIB as a downstream target of c-Myc, which directly regulates its expression and contributes to tumor aggressiveness and rapid metastases [35]. However, we have shown that miR-212-3p has a deregulatory effect on c-Myc. To delineate if NFIB inhibition plays a role in Myc regulation, we silenced NFIB in group $3 \mathrm{MB}$ cells using transient siRNA-NFIB treatment. As with miR-212-3p stable expression, NFIB silencing decreased total c-Myc levels with a concomitant decrease in phosphorylation of c-Myc at S62 and T58; moreover, upstream c-Myc regulators i.e. p-Akt and p-Erk, were also significantly reduced (Fig. 5C).

Given the direct inhibitory effect of miR-212-3p on c-Myc and NFIB's promoting role in metastasis, we sought to study the effect of the miR-212-3p/NFIB axis

(See figure on next page.)

Fig. 3 Effect of miR-212-3p expression on c-Myc regulation, cell cycle progression and apoptosis in group 3 MB cancer cells. A Western blotting analysis of c-Myc stimulatory signals showing a shift in c-Myc phosphorylation states from serine-62 (active form) to threonine-58 (inactive form) in miR-212-3p transiently transfected HDMB03 cells. In dox-induced stable miR-212 expression, total c-Myc was reduced. Upstream activators of c-Myc, i.e., p-Akt and p-Erk, also destabilized upon miR-212-3p restoration. B Cell cycle analysis by propidium iodide (PI) staining showing arrest at $\mathrm{G}_{0} / \mathrm{G}_{1}$ phase in miR-212-3p transiently transfected $\mathrm{HDMB03}$ cells. C Western blotting analysis demonstrating reduced expression of $\mathrm{G}_{0} / \mathrm{G}_{1}$ regulatory checkpoint proteins, CDK4, CDK6, and cyclin D1, but not CDK2, in miR-212-3p transiently transfected HDMB03 cells. D Elevated expression of pro-apoptotic binding partners of c-Myc, i.e., Bin-1 and p19ARF, concurrent with expression of apoptotic proteins (cleaved PARP and cleaved caspase-3) in miR-212-3p restored HDMB03 cells. E Annexin-Cy5 and PI staining confirming increased apoptosis (early and late) in miR-212-3p transiently transfected HDMB03 cells compared to scramble control. $\beta$-actin served as an internal loading control. Data presented as mean \pm SD from experiments done in triplicate and analyzed using Student's t-test; ${ }^{*} p<0.05,{ }^{* *} p<0.01,{ }^{* * *} p<0.001$ 
(A)

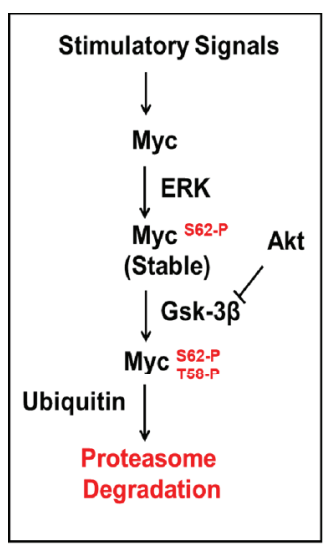

HDMB03 CELLS

HDMB03 CELLS

HDMB03 CELLS

miR-212 Mimic

Dox (500ng/ml)

Dox $(500 \mathrm{ng} / \mathrm{ml})$

(B)
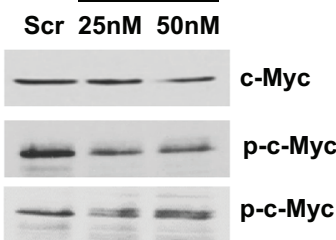

p-c-Myc (S62)

p-c-Myc (T58)

$+\quad+$

p-Akt (S473)

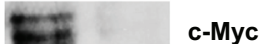

$+\quad+$

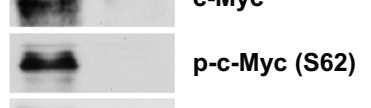

$\longrightarrow$ p-Akt (S473)

$\longrightarrow$ Akt

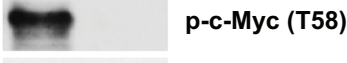

$\longrightarrow$ Akt

$=\mathrm{p}$-Erk

$=$ Erk

$-\cdots$ p-Erk

$\longrightarrow-\beta$-Actin

\begin{tabular}{|c|c|c|c|}
\hline \multirow{2}{*}{ Ratio } & \multirow{2}{*}{ Scr } & \multicolumn{2}{|c|}{ miR-212-3p Mimic } \\
\cline { 3 - 4 } & & $25 \mathrm{nM}$ & $50 \mathrm{nM}$ \\
\hline p-T58:p-S62 & 1 & 2.35 & 3.18 \\
\hline
\end{tabular}
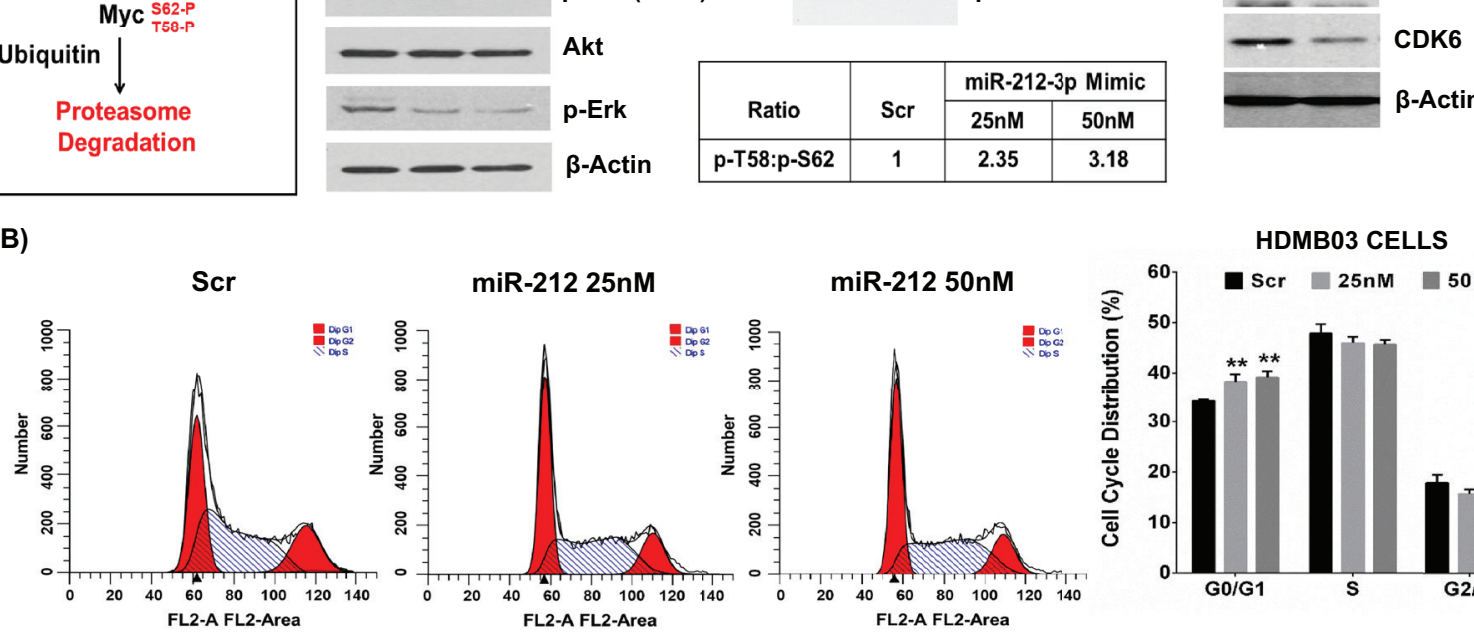

miR-212 25nM
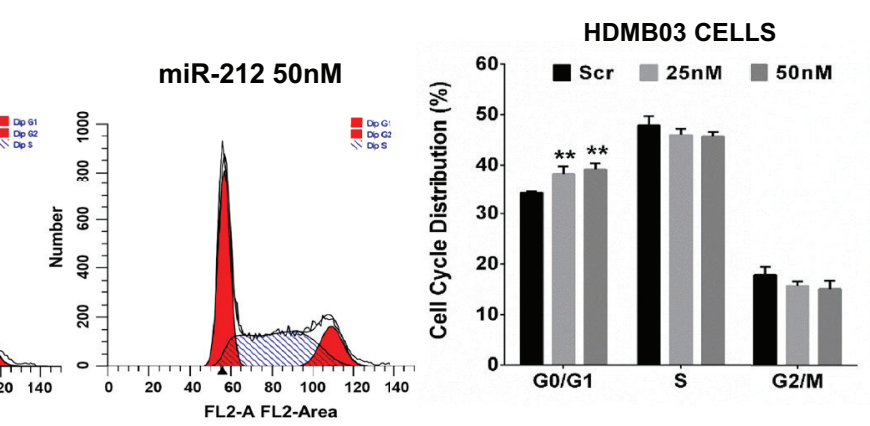

(C)

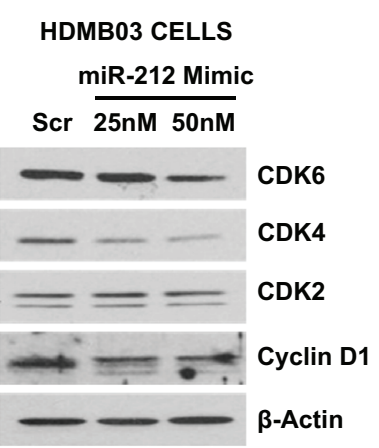

(D)

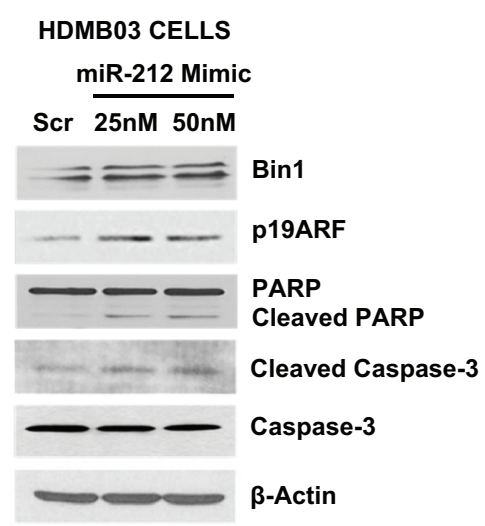

miR-212 25nM

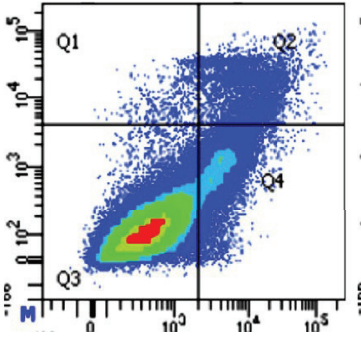

Annexin V-Cy5

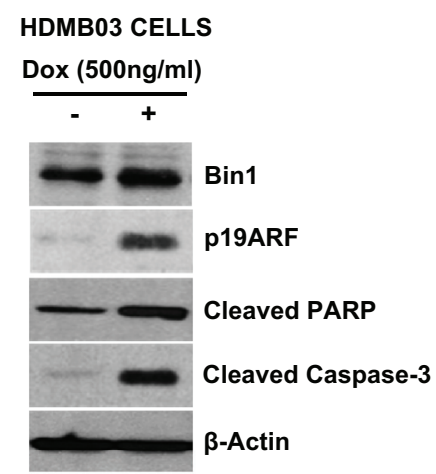

HDMB03 CELLS

Actin

(E)

Scr

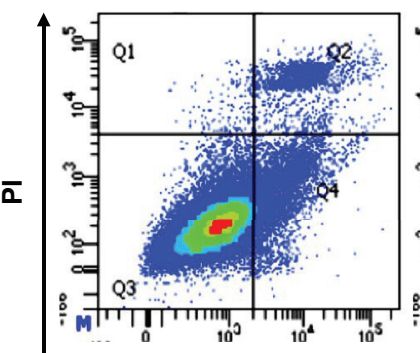

miR-212 50nM

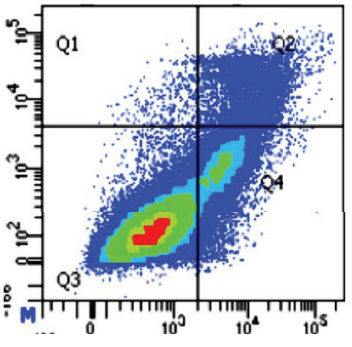

HDMB03 CELLS

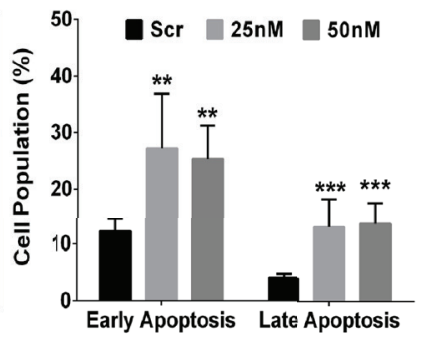

Fig. 3 (See legend on previous page.) 
on cancer stem cell (CSC) maintenance and self-renewal. We first analyzed the expression of stem cell markers in miR-212-3p stably-expressing and NFIB-silenced HDMB03 cells. RT-PCR and Western blotting analyses revealed concurrent de-regulation in the expression of several stem cell markers, including CD133, $\beta$-catenin, Sox-2, Oct-4, and Nanog (Fig. 5D and E). CSCs selfrenewal ability was further assessed through tumor sphere-forming assay. Again, in both NFIB-silenced and miR-212-3p stably-expressing cancer cells, substantially decreased numbers of spheres were noted (Fig. $5 \mathrm{~F}$ and G). These results further elucidated the anti-neoplastic properties of miR-212-3p with its inhibitory role on CSC maintenance and implicated NFIB as a strong oncogenic target of miR-212-3p in group 3 tumors.

\section{Restoration of miR-212-3p expression inhibits the growth of orthotopic group $3 \mathrm{MB}$ tumors}

To determine the role of miR-212-3p in group $3 \mathrm{MB}$ tumor growth and progression in vivo, we implanted stable miR-212-inducible HDMB03 cells into the cerebellum of mice as detailed in Fig. 6A. MiR-212-3p expression was restored in mice via daily doxycycline supplementation (oral gavage). At day 16, Dox-fed mice showed significant reduction in tumor growth compared to control (Fig. 6B and C). Moreover, Kaplan-Meier survival analysis revealed significantly higher survival in the Dox-fed group compared to control (Fig. 6D). Tumor histology revealed smaller tumor margins in Dox-fed mice compared to control (Fig. 6E). In addition, Dox-fed mice developed tumors with substantially reduced staining for Ki-67, c-Myc, and NFIB with a concomitant increase in staining for cleaved caspase-3 (Fig. 6F). These in vivo results substantiated the anti-proliferative, pro-apoptotic, and tumor-suppressive properties of miR-212-3p (Fig. 6G) in group $3 \mathrm{MB}$ tumors.

\section{Discussion}

Haploinsufficiency of chromosome 17p bestows a highrisk phenotype upon group 3 tumors [3, 25, 45]. Several loci populated by tumor suppressor genes can be found within the afflicted short arm. Studies have linked few genes residing on the terminal locus (17p13.3) with $\mathrm{MB}$, such as ROX/MNT [7] or HIC1 [51]. None have studied microRNAs on this locus. We previously elucidated the anti-neoplastic properties and oncogenic targets of miR1253, a microRNA found on the terminal part of this locus, in MB [24]. In the present study, we have described the tumor-suppressive properties of miR-212-3p in group $3 \mathrm{MB}$; we have additionally identified a target with strong oncogenic potential.

An initial in silico analysis of a publicly available MB dataset revealed significantly reduced expression for miR-212-3p compared to normal. These findings were specifically recapitulated in non-SHH/WNT tumors both in pediatric samples (ex vivo) and in classic MB cell lines (in vitro). Focusing on the higher risk group 3 tumors, we sought a mechanism for miR-212-3p silencing. In many cancers, microRNAs undergo epigenetic silencing via hypermethylation along $\mathrm{CpG}$ islands or chromatin

\section{(See figure on next page.)}

Fig. 4 Isolating oncogenic targets of miR-212-3p in group 3 MB tumors. A Venn diagram showing 37 common targets between miRNA target prediction databases (Targetscan and miRDip) and genes downregulated ( $\log _{2}$ fold change $<-1.0, p<0.05$ ) in miR-212 expressing HDMB03 cells (via RNA sequencing analysis). B Expression heat map of the 37 identified targets of miR-212 in two MB data sets, (i) local (pediatric cerebellum $n=10$; group $3 \mathrm{MB} n=7$; Kanchan et al., GSE148390) and (ii) larger meta-dataset (normal cerebellum $n=291$; group 3 MB $n=233$; Weishaput et al., GSE124814). C Elevated expression of NFIB across MB datasets (NC $n=9$, Roth et al. 2008; MB1 $n=76$, Gilbertson et al. 2012; MB2 $n=223$, Pfister et al. 2017; MB3 $n=57$, Delattre et al. 2012; MB4 $n=62$, Kool et al. 2009). D Elevated NFIB expression across subgroups within local MB cohort (pediatric NC $n=10 ; \mathrm{SHH} n=6$; group $3 \mathrm{n}=7$; group $4 \mathrm{n}=12$; Kanchan et al., GSE148390). E Kaplan-Meier Survival Analysis demonstrating poor survival in high NFIB-expressing MB patients $(n=542)$ compared to low-expressing patients $(n=70)$ (Cavalli et al., GSE85217). F Western blotting showing significantly increased expression of NFIB in classic group 3 MB cell lines (HDMB03, D425, and D341). G Immunohistochemical staining of NFIB showing intense nuclear expression in group 3 MB patient samples $(n=9)$ when compared to normal cerebellum $(n=8)$. $\mathbf{H}$ Dual-luciferase assay confirming NFIB as a direct target of miR-212-3p. I RT-PCR and $\mathbf{J}$ Western blotting analysis showing significantly decreased expression of NFIB in miR-212-3p transiently transfected HDMB03 cells. $\beta$-actin served as an internal loading control. Data presented as mean \pm SD from experiments done in triplicate and analyzed using Mann-Whitney $\mathrm{U}$ test $(\mathbf{C}$ and $\mathbf{D})$ or Student's t-test $(\mathbf{E}, \mathbf{G}$, and $\mathbf{H}) ;{ }^{*} p<0.05,{ }^{* *} p<0.01,{ }^{* * *} p<0.001$. Scale bar: $100 \mu \mathrm{m} . \mathrm{NC}$, normal cerebellum 


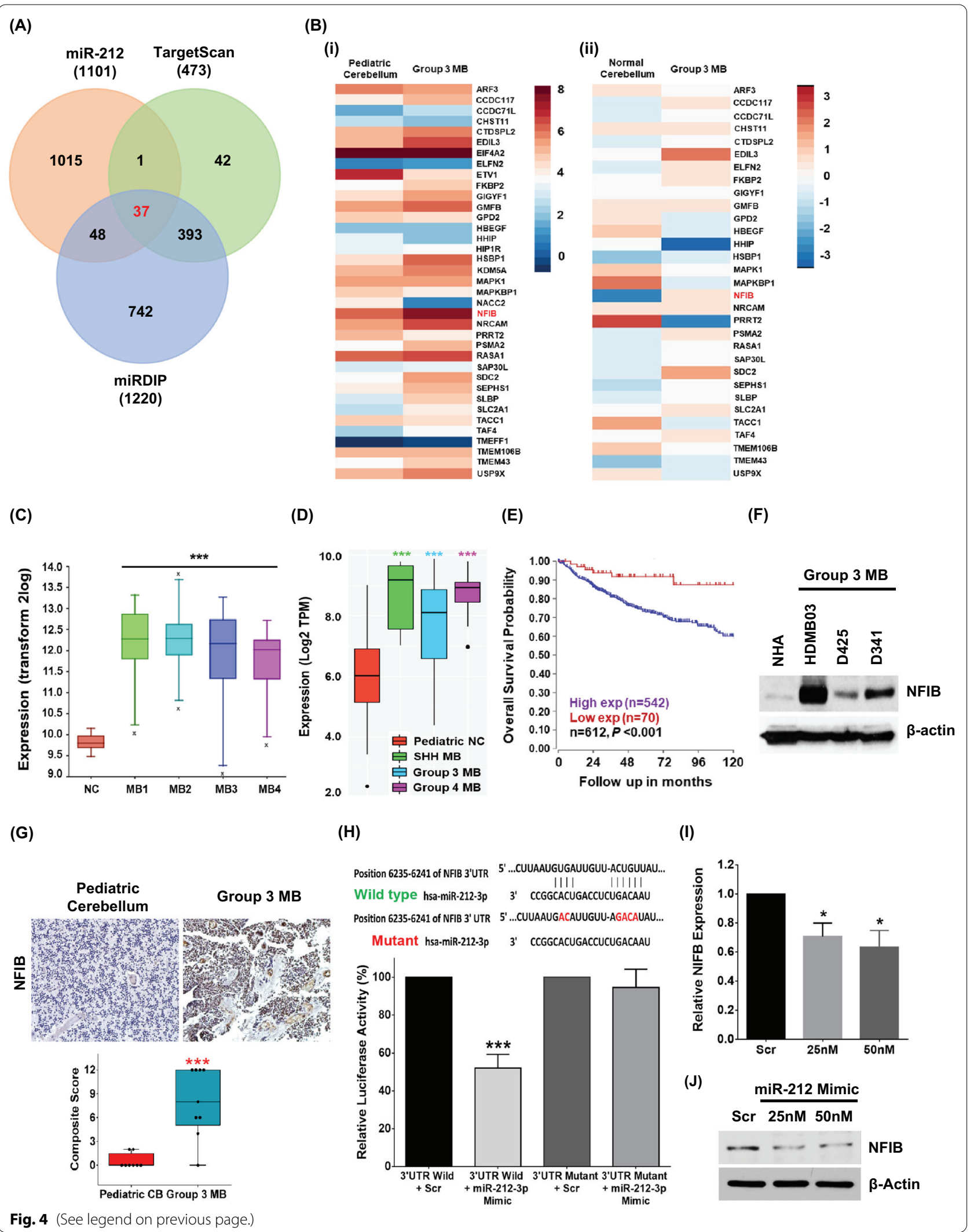


rearrangement through histone modifications [24, 26]. Methylation profiling in high-risk tumors showed no differences in methylation pattern of the miR-212-3p locus between tumors and normal tissue. Contrarily, histone modifications at critical lysine residues within miR212-3p provided compelling evidence for an epigenetic silencing mechanism. More specifically, increased methylation at H3K27 and H3K9 and a concomitant decline in acetylation of H3K9 was shown by ChIP-RT-PCR. Either treatment with HDAC inhibitors or EZH2 silencing reliably restored miR-212-3p expression. Together, these data revealed miR-212-3p silencing in group 3 tumors and assigned an epigenetic mechanism via histone modifications. Our findings aligned with prior reported patterns of miR-212-3p epigenetic silencing in lung cancer [19].

Restoring miR-212-3p expression in group $3 \mathrm{MB}$ cells by either transient transfections or stable induction resulted in a cadre of anti-neoplastic effects. First, cancer cell proliferation, wound healing, migration, and colony formation were significantly reduced. Subsequently, cell proliferative markers, p-Akt and p-Erk, were downregulated in miR-212-3p restored cells, eventually leading to cell cycle arrest $\left(G_{0} / G_{1}\right.$ cell cycle phase) with dysregulated expression of checkpoint regulatory kinases, CDK4, CDK6, and cyclin D1. Next, we revealed regulatory effects of miR-212-3p on c-Myc phosphorylation states, with transient expression resulting in a shift in phosphorylation patterns from S62 (active, favoring proliferation) to T58 (inactive, favoring apoptosis), and stable expression leading to a near-abrogation in total c-Myc expression. Of note, p-Akt and p-Erk, which were downregulated by both transient and stable miR-212-3p expression, are upstream kinases that phosphorylate c-Myc at S62, rendering it resistant to degradation [14, 23]. Moreover, in miR-212-3p-expressing cells, key apoptotic binding partners of c-Myc, p19 $9^{\mathrm{ARF}}$ and Bin-1, were elevated in tandem with cleaved PARP and cleaved caspase-3, resulting in a high apoptotic signal in cancer cells. As prior, our results aligned with studies on miR-212-3p in colorectal cancer [34], nasopharyngeal carcinoma [20], and lung cancer [21] where similar effects were seen on cancer cell proliferation, migration and invasion, cell cycle arrest, and apoptosis. Given the high association between c-Myc amplification and poor prognosis in group $3 \mathrm{MB}[3,45]$, our data suggested a plausible mechanism contributing to high-risk MB aggressiveness, wherein silencing miR-212-3p may lift its regulation of c-Myc, allowing for unchecked Myc-driven signaling.

We next identified an oncogenic target of miR-212-3p using in silico, ex vivo, and in vitro approaches. In so doing, we revealed Nuclear Factor I/B (NFIB), a transcription factor that can bind to specific overlapping DNA repeat sequences ( $5^{\prime}$-TTGGCNNNNNGCCAA-3') throughout the genome to activate transcription and replication, most notably in normal lung and brain development $[16,49]$. In fact, the 14 target genes of miR-212 isolated via high-throughput analyses of independent $\mathrm{MB}$ datasets seemed most intricately involved in these processes (Additional file 6: Fig. S4B). Given the association of high NFIB expression in group 3 tumors with poor survival, we showed that silencing NFIB expression dramatically decreased cancer cell proliferation, migration, and invasion in vitro. Similar effects have been shown for NFIB in gastric cancers [53], TNBC [29], SCLC [47], and colorectal cancer [30]. In colorectal cancer, melanoma, and gastric cancers, overexpression of NFIB was associated with epithelial-mesenchymal transition (EMT), migration and invasion $[13,30,53]$. In melanoma, specifically, NFIB-targeted upregulation of EZH2 led to the epigenetic silencing of MITF, promoting a highly invasive phenotype [13]. In SCLC, NFIB overexpression cooperated with $\mathrm{Rb} / \mathrm{p} 53$ deletion to increase chromatin

(See figure on next page.)

Fig. 5 Effect of NFIB silencing on cancer cell phenotype in group 3 MB. A Transient silencing of NFIB (siRNA-NFIB, 20 nM) showing significant reduction in HDMB03 cell viability compared to siRNA-control cells. B Transwell migration/invasion assay recapitulating the same with decreased migrating and invading cells in siRNA-NFIB-treated cells compared to control. C Western blotting analysis of c-Myc showing reduction in total c-Myc, p-S62, p-T58 and reduction in upstream activators of c-Myc, i.e., p-Akt and p-Erk. RT-PCR and Western blotting analyses demonstrating reduced stem cell markers, i.e. Nanog, Oct4, Sox2, CD133 and $\beta$-catenin, in D siRNA-NFIB-treated HDMB03 cells and $\mathbf{E}$ Dox-treated stably-expressing miR-212-3p HDMB03 cells. Medullosphere assays demonstrating dramatically reduced sphere formation in $\mathbf{F}$ siRNA-NFIB-treated and $\mathbf{G}$ Dox-treated stably-expressing miR-212-3p HDMB03 cells. $\beta$-actin served as an internal loading control. Data presented as mean \pm SD from experiments done in triplicate and analyzed by Student's t-test; ${ }^{*} p<0.05 ;{ }^{* *} p<0.01 ;{ }^{* * *} p<0.001$. Scale bar: $100 \mu \mathrm{m}$ 


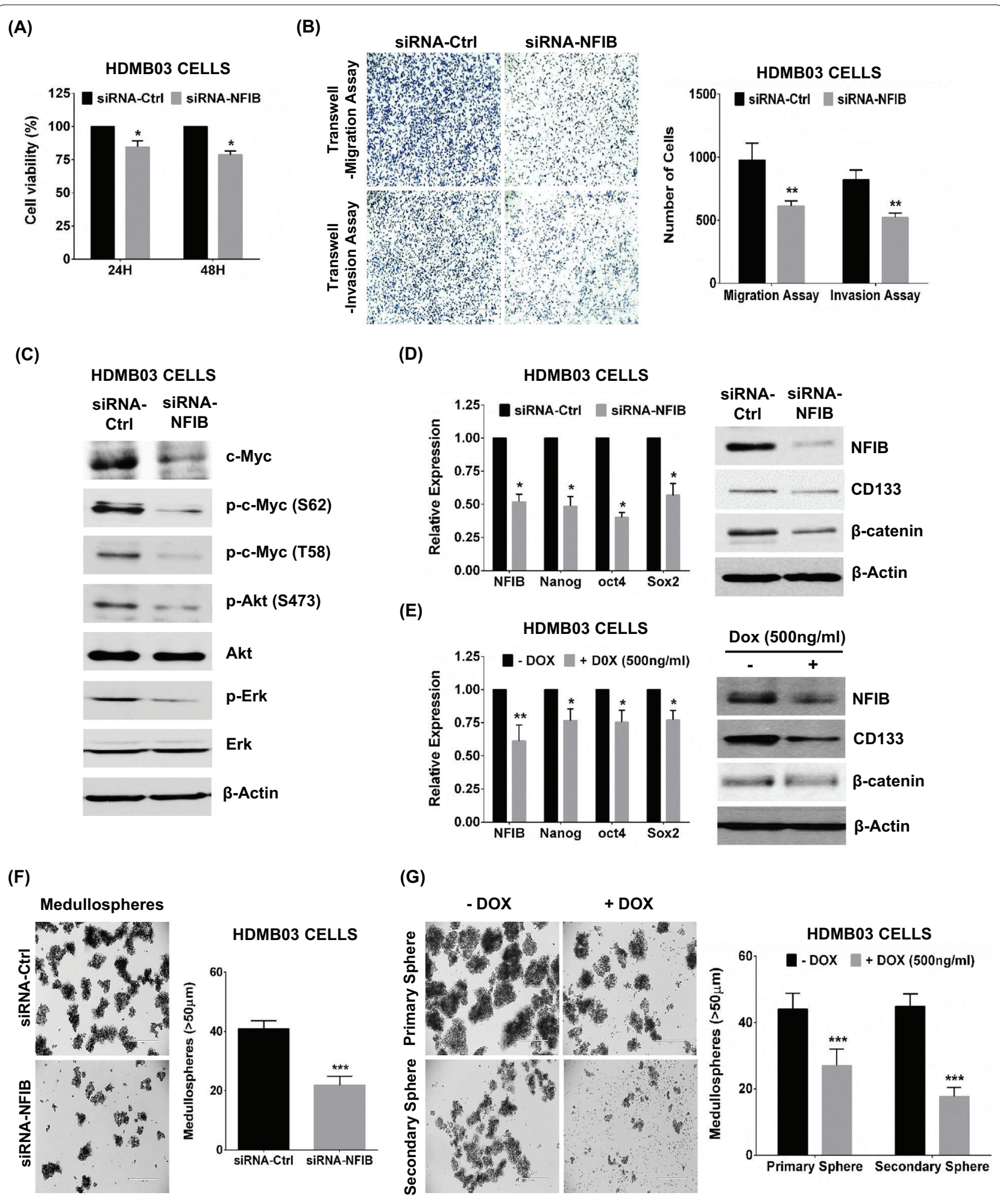

Fig. 5 (See legend on previous page.) 
accessibility to pro-metastatic genes. Moreover, c-Myc was shown to regulate NFIB in SCLC and further contribute to rapid metastases [35].

Metastases at diagnosis and tumor recurrence are cardinal prognostic features contributing to dramatically increased mortality in group $3 \mathrm{MB}[3,25,38,43-45]$. $\mathrm{MB}$ recurrent tumors, either in the primary or metastatic site, derive from a subpopulation of cancer stem cells (MBSCs), which can evade current chemotherapeutics and radiation therapy [1]. MBSCs express stemness markers, such as CD133, CD15, and Sox2, and can possess an inordinate capacity to form aggressive tumors with increased self-renewal ability, facilitating MB relapse and rapid demise $[48,50]$. In NFIB-silenced and miR212-3p restored group $3 \mathrm{MB}$ cells, we noted decreased expression of stemness markers, i.e. CD133, Sox2, Oct4, Nanog, and $\beta$-catenin, concurrent with reduced tumor cell self-renewal capacity as evidenced by sphere-forming assays. These results introduce miR-212-3p's role in hampering MBSC maintenance and self-renewal, possibly through NFIB regulation.

These in vitro findings were translated into an orthotopic mouse model wherein miR-212-3p induction led to significantly smaller tumors and substantially elevated survival. Moreover, miR-212-3p-expressing tumors exhibited decreased staining for Ki-67, c-Myc, and NFIB and elevated staining for cleaved caspace-3, strengthening our hypothesis of the tumor-suppressive role of miR212 in group $3 \mathrm{MB}$ tumors.
Intriguingly, we have shown EZH2 as an upstream regulator of miR-212-3p and revealed miR-212-3pmediated destabilization of c-Myc. At the core of these critical contributors to tumor aggressiveness lies NFIB, a downstream target of c-Myc (SCLC [35]) and an inducer of EZH2 (melanoma [13]). Whether NFIB plays a role in inducing EZH2 in group 3 tumors to epigenetically silence miR-212-3p, in turn stabilizing c-Myc, is an important mechanism that is being presently evaluated in detail.

\section{Conclusions}

This study has uncovered a novel tumor suppressor gene in group $3 \mathrm{MB}$, i.e. miR-212-3p. We have shown expression silencing by histone modifications, as opposed to hypermethylation. The anti-neoplastic properties of miR212-3p were exhibited by destabilization of c-Myc, cancer cell arrest at $\mathrm{G}_{0} / \mathrm{G}_{1}$ cycle, and robust apoptosis, resulting in attrition in cancer cell invasiveness and tumor growth with improved survival in vivo. By targeting NFIB, a wellstudied metastatic driver [8], a regulator of EZH2 [13], and downstream effector of c-Myc [35], miR-212-3p decreased cancer cell aggressiveness, stem cell maintenance, and renewal. Our studies provide support for the use of miRNA-based therapies as a targeted approach to not only addressing group $3 \mathrm{MB}$ tumor aggressiveness but also unburdening young patients from the harmful side-effects of current cytotoxic therapies.

(See figure on next page.)

Fig. 6 Effect of miR-212-3p expression on in vivo tumorigenicity. A Experimental schema depicting generation of orthotopic group 3 MB mouse model with stable Dox induction of miR-212-3p. B Bioluminescence images of mice with tumors showing tumor growth on specified days (Day 0,8 and 16). All images were adjusted to the bioluminescence scale bar shown (Radiance ( $\mathrm{p} / \mathrm{sec} / \mathrm{cm}^{2} / \mathrm{sr}$ ); Color scale-Min: $\left.1.50 \mathrm{e}^{4} ; \mathrm{Max}: 1.50 \mathrm{e}^{6}\right)$. C Graphical quantification of total photon flux (Photons/second) emitted by tumors on indicated days (Day 0,8 and 16) between mice with or without Dox treatment, i.e. with or without miR-212-3p expression, respectively. D Kaplan-Meier survival analysis of mice with orthotopic tumors showing dramatically attenuated survival in control group (without miR-212-3p induction). E Representative histologic images (hematoxylineosin stained paraffin sections) of intra-cranial tumors in control and Dox-treated mice. a and c Area marked (red, $1000 \mu \mathrm{m}$ ) delineates margins of invading tumor. $\mathbf{b}$ and $\mathbf{d}$ Magnified images of representative tumor area of $\mathbf{a}$ and $\mathbf{c}$ (yellow, $100 \mu \mathrm{m}$ ). F Representative images of Ki-67, c-Myc, $\mathrm{NFIB}$ and cleaved caspase-3 staining from control and Dox-treated tumors. G Schematic representation depicting the tumor suppressive actions of miR-212-3p in group 3 MB. Data presented as mean \pm SD from experiments done and analyzed by Student's t-test; ${ }^{*} p<0.05 ;{ }^{* *} p<0.01 ;{ }^{* * *} p<0.001$. Kaplan-Meier survival compared between groups by the Log Rank test ( $p=0.0153$ ). Scale bar: $100 \mu \mathrm{m}$ 
(A) Stable Inducible-miR-212

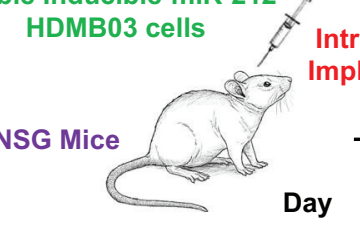

tracranial plantation

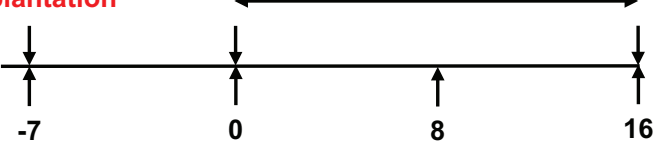

IVIS Imaging

(B)

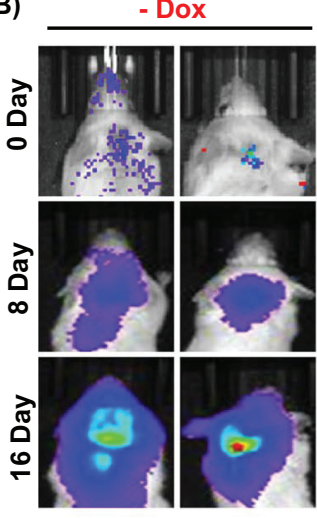

(E)

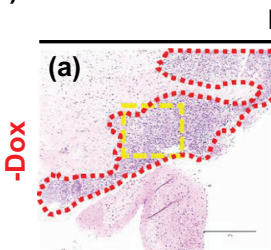

(G)
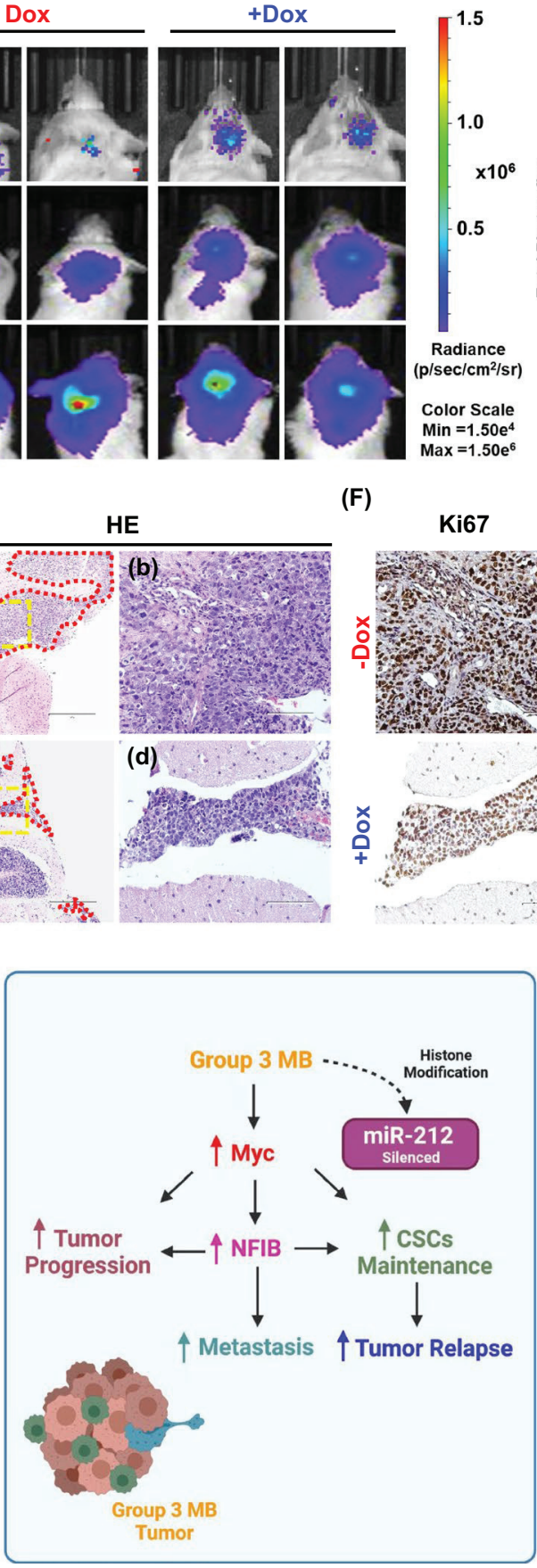
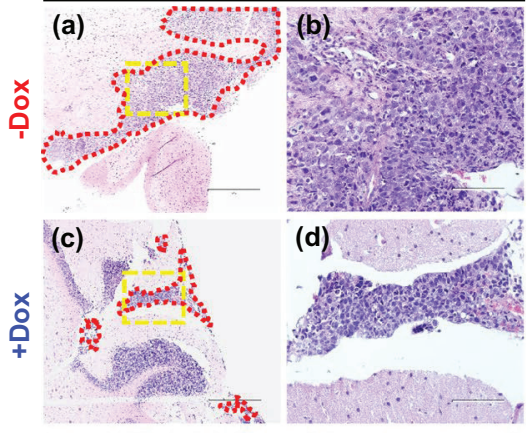

(d)

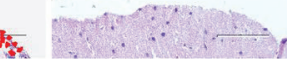

(C)

(D)

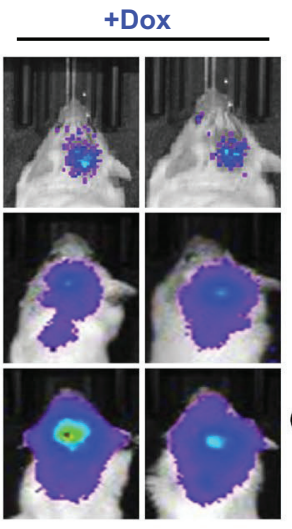

(F)

Ki67
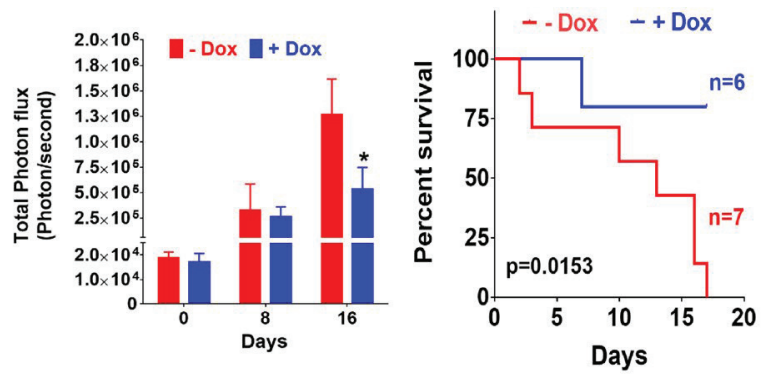

NFIB

Cleaved Caspase-3

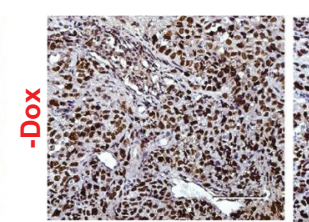

c-Myc

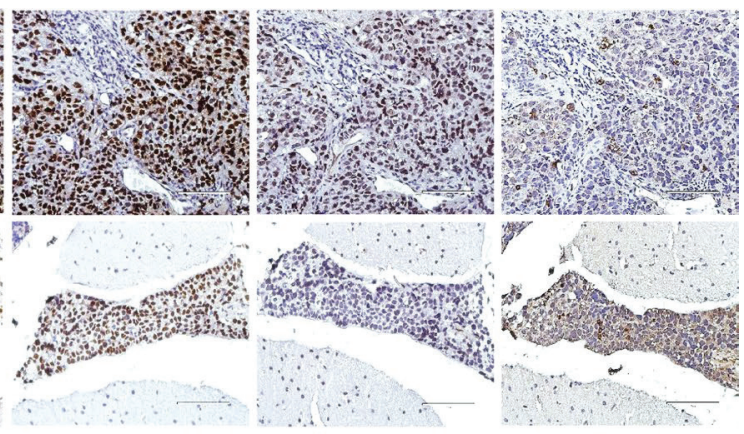

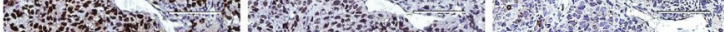

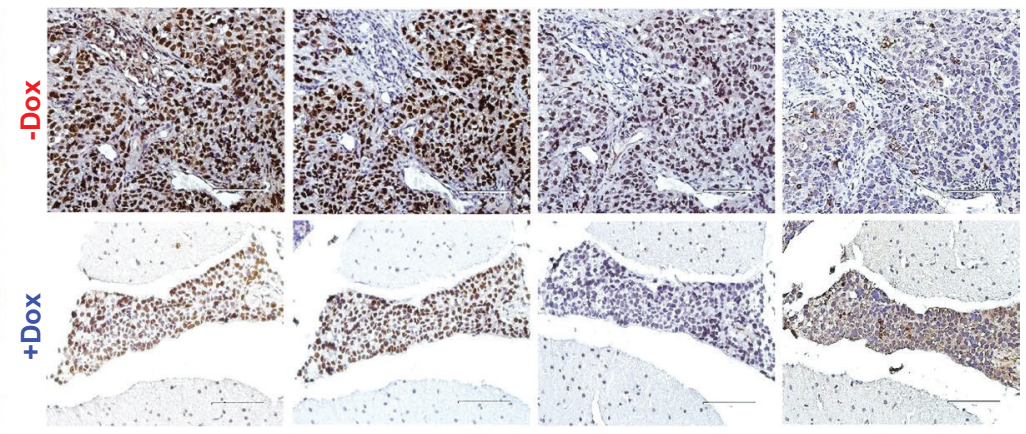

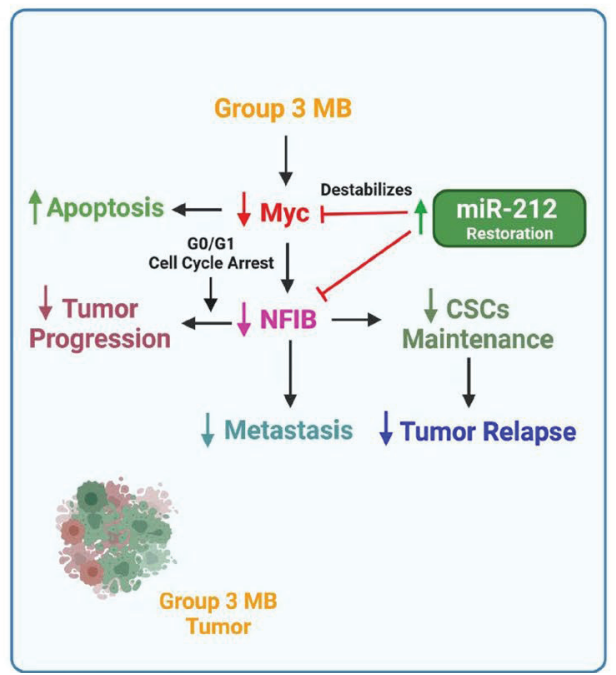

Fig. 6 (See legend on previous page.) 


\section{Abbreviations}

3'UTR: 3' Untranslated region; 5-AzaC: 5-Aza-2'-deoxycytidine; AKT: Protein kinase B; ANOVA: Analysis of variance; Bin-1: Myc box-dependent-interacting protein 1; C-Myc: Avian myelocytomatosis virus oncogene cellular homolog; CB: Cerebellum; CDK4: Cyclin-dependent kinase 4; CDK6: Cyclin-dependent kinase 6; CNS: Central nervous system; MBSC: Medulloblastoma stem like cells; CTGF: Connective tissue growth factor; DNA: Deoxyribonucleic acid; EMT: Epithelial-mesenchymal transition; EZH2: Enhancer of zeste homolog 2; FACS: Fluorescence-activated cell sorting; FFPE: Formalin-fixed paraffin-embedded; FISH: Fluorescence in situ hybridization; HIC1: Hypermethylated in cancer-1; HCC: Hepatocellular carcinoma; HDAC: Histone de-acetylase; HRP: Horseradish peroxidase; i(17q): Isochromosome 17q; IHC: Immunohistochemistry; IRB: Institutional Review Board; MB: Medulloblastoma; miR: MicroRNA; miR-212-3p: MicroRNA 212-3p; miR-1253: MicroRNA 1253; MITF: Microphthalmia-associated transcription factor; MNT: Max network transcription factor; MTT: 3-(4, 5-Dimethylthiazol-2-yl)-2, 5-diphenyl-2H-tetrazolium bromide; NFIB: Nuclear factor I/B; NI: Normal; Non-SHH/WNT: Non-sonic hedgehog/non-wingless; NSCLC: Non-small cell lung cancer; Oct4: Octamer-binding transcription factor-4; p19 ARF: P19 alternative reading frame protein; p-Akt: Phosphorylated protein kinase B; PARP: Poly ADP ribose polymerase; PCR: Polymerase chain reaction; Ped: Pediatric; p-Erk: Phosphorylated extracellular signal related kinase; PI3K: Phosphoinositide 3-kinase; RNA: Ribonucleic acid; SCLC: Nonsmall cell lung cancer; SHH: Sonic hedgehog; SD: Standard deviation; SGK3: Serum and glucocorticoid-inducible kinase 3; SMYD4: SET and MYND domain containing 4; Sox-2: Sry-box transcription factor-2; TCF7L2: Transcription factor 7-like 2; TNBC: Triple-negative breast cancer; TSA: Tricostatin A; WNT: Wingless.

\section{Supplementary Information}

The online version contains supplementary material available at https://doi. org/10.1186/s40478-021-01299-z.

\section{Additional file 1: Supplemental Methods}

Additional file 2: Fig. S1. Exploring epigenetic silencing of miR-212-3p in group 3 MB tumors. (A) Frequency distribution of cytogenetic aberrations (haploinsufficiency of 17p, i17q, c-Myc amplification) in (i) our local cohort of $\mathrm{MB}$ tumors $(\mathrm{SHH} n=9$; group $3 \mathrm{MB} n=10$; group $4 \mathrm{MB} n=16$; Kanchan et al., GSE148390). (ii) Distinguishing features of high-risk tumors compared between our local cohort (Kanchan et al., GSE148390) and a larger dataset (Cavalli et al., GSE85217). (B) DNA methylation profile of local cohort of group $3(n=6)$ and group $4(n=11)$ MB tumors showing lack of perturbations to methylation in the promoter region of miR-212-3p compared to normal pediatric cerebellum $(n=4)$; further demonstrable in vitro by a lack of expression restoration with de-methylation by 5 -AzaC (5 $\mu \mathrm{M})$ in HDMB03 cells. (C) Recapitulation of elevated HDAC and EZH2 expression complementing prior in silico data in a large MB meta-dataset (NC n=291, group 3 MB n=233; Weishaupt et al., GSE124814). (D) RTPCR analysis in pan-HDAC-treated D425 cells (TSA, 100 nM; Belinostat, 1 $\mu \mathrm{M}$; and Vorinostat, $1 \mu \mathrm{M}$ ) showing elevated expression of miR-212-3p. RNU6B set as an endogenous control. Western blotting analysis showed increased acetylated a-tubulin in pan-HDAC inhibitors treated D425 cells. $\beta$-actin served as an internal control. Results presented as mean \pm SD from experiments done in triplicate and analyzed using Student's t-test (B and $\mathbf{D}$ ) or Mann-Whiteny U test $(\mathbf{C}) ;{ }^{*} p<0.05,{ }^{* *} p<0.01,{ }^{* * *} p<0.001$. NC, normal cerebellum; $d x$, diagnosis

Additional file 3: Fig. S2. Effect of miR-212-3p expression on SHH MB cancer cells. (A) RT-PCR analysis showing increased miR-212-3p expression via transient transfection in Daoy cells. Growth restrictive properties demonstrable by (B) cell proliferation (MTT) and (C) colony formation assays in miR-212-3p transfected Daoy cells. Data presented as mean \pm SD from experiments done in triplicate and analyzed using Student's t-test; ${ }^{*} p<0.05,{ }^{* *} p<0.01,{ }^{* * *} p<0.001$.

Additional file 4: Fig. S3. Deregulated pathways associated with miR212-3p silencing in group 3 MB. (A) Bubble plot (FunSet plot) representing 12 clusters of significantly enriched $\mathrm{GO}$ biological processes. FunSet employs hypergeometric test to perform the enrichments and additionally uses semantic similarity measure with Aggregate Information Content (AIC) index to cluster highly similar GO terms [17]. (B) Enriched biological pathways associated with miR-212-3p silencing identified using Enrichr (https://maayanlab.cloud/Enrichr/) [4] highlighting regulation of cell cycle phase transition as the most enriched pathway in miR-212-3p overexpressed HDMBO3 cells

Additional file 5: Table S1. Genes (and associated pathways) enriched by miR-212-3p expression restoration in HDMB03 cells. Detailed gene list for selected clusters of significantly enriched $\mathrm{GO}$ biological processes represented in Additional file 4: Fig. S3A. Presented clusters were selected based on $-\log _{10}$ FDR values with threshold $p<0.05$

Additional file 6: Fig. S4. Putative oncogenic targets of miR-212-3p and their associated pathways in group $3 \mathrm{MB}$ tumors. (A) Expression analysis by RNA Sequencing of isolated miR-212-3p targets (37 genes) in local cohort of group $3 \mathrm{MB}$ tumors (pediatric $\mathrm{CB} n=10$; group $3 \mathrm{MB} n=7$; Kanchan et al., GSE148390). Those observed to be significantly elevated in group 3 tumors were the following 14 genes: CCDC71L, CTDSPL2, EDIL3, GIGYF1, HSBP1, KDM5A, NFIB, NRCAM, PSMA2, SDC2, SEPHS1, TAF4, TMEM43, and USP9X. (B) Enriched cellular/biological pathways associated with these targets identified using FunSet tool [17]. (C) Expression of NFIB across MB subgroups in a large MB meta-dataset (NC $n=291$; WNT $n=118$; SHH MB n=405; group $3 \mathrm{MB} n=233$; group $4 \mathrm{MB}, \mathrm{n}=530$; Weishaupt et al., GSE124814). Box plots (A) represent gene expression ( $\log _{2}$ Transcripts Per Million) and were analyzed using Mann-Whiteny $U$ test; ${ }^{*} p<0.05,{ }^{* *} p$ $<0.01,{ }^{* *} p<0.001$. Pathways represented as an inverted bar graph based on the $-\log _{10}$ FDR values with threshold $p<0.05$ (red dashed line). $C B$, cerebellum; NC, normal cerebellum.

Additional file 7: Table S2. Isolating a strong oncogenic target of miR212-3p. Further analysis of putative miR-212-3p targets by examining conserved binding sites, confirming elevated expression in 2 independent MB cohorts, and examining effect of high expression on survival. In the table, ' $x$ ' denotes inclusion criteria, and '-' denotes no expression data found in dataset.

\section{Acknowledgements}

We would like to acknowledge Drs. Deborah Perry and Michael Punsoni for assisting with procuring tumor samples for the study. The overall scheme in Fig. $6 \mathrm{G}$ was created with BioRender.com. We would further like to acknowledge the contribution of our funding sources to this study.

\section{Authors' contributions}

NP: Conceptualization, Data curation, Formal analysis, Investigation, Methodology, Validation, Visualization, Writing - Original draft preparation; RK: Investigation, Methodology, Writing_review and editing; DD: Data curation, Formal analysis, Methodology, Visualization, Writing — review and editing; NB: Data curation, Methodology, Visualization; PA: Data curation, Formal analysis, Methodology, Visualization; RC: Data curation, Formal analysis, Methodology, Visualization; IT: Data curation, Formal analysis, Methodology, Visualization, Writing —review and editing; RV: Investigation, Methodology, Writing—review and editing; SKM: Investigation, Methodology; DK: Data curation, Formal analysis, Investigation, Methodology, Visualization; GAT: Formal analysis, Visualization; MWN: Writing —review and editing; SKB: Project administration, Resources, Supervision, Writing — review and editing; SM: Conceptualization, Data curation, Formal analysis, Funding acquisition, Methodology, Project administration, Supervision, Visualization, Writing — review and editing. All authors read and approved the final manuscript.

\section{Funding}

This work was supported by an American Cancer Society Seed Grant to the Fred \& Pamela Buffett Cancer Center, which is funded by a National Cancer Institute Cancer Center Support Grant (P30 CA036727); the Nebraska Department of Health and Human Services via Grants LB506 and LB606; and the Team Jack Brain Tumor Foundation. None of the funding bodies engaged in study design, data collection, interpretation, analysis, or manuscript preparation.

\section{Availability of data and materials}

Datasets generated by the current study are available from the corresponding author on reasonable request. Datasets used and analyzed during the current study are available in the Gene Expression Omnibus (GEO). These include 
Kanchan et al., GSE148390; Drusco et al., GSE62381; Roth et al., GSE3526; Gilbertson et al., GSE37418; Kool et al., GSE10327; Weishaupt et al., GSE124814; and Cavalli et al., GSE85217.

\section{Declarations}

\section{Ethics approval and consent to participate}

Normal cerebellum and pediatric MB samples were collected after approval from the Institutional Review Board of the University of Nebraska Medical Center (IRB \# 561-16-EP). All experimental animal procedures were approved by the Institutional Animal Care and Use Committee (IACUC \# 16-052-06-FC).

\section{Consent for publication}

Our manuscript does not contain any individual person's data in any form so consent for publication is not applicable.

\section{Competing interests}

The authors declare that they have no competing interests.

\section{Author details}

'Department of Biochemistry and Molecular Biology, University of Nebraska Medical Center, Omaha, NE 68198, USA. ${ }^{2}$ Department of Biomedical Sciences, Creighton University School of Medicine, Omaha, NE 68124, USA. ${ }^{3}$ Department of Ophthalmology and Visual Sciences, Washington University School of Medicine, St. Louis, MO 63110, USA. ${ }^{4}$ School of Interdisciplinary Informatics, University of Nebraska at Omaha, Omaha, NE 68182, USA. ${ }^{5}$ Department of Pathology and Microbiology, University of Nebraska Medical Center, Omaha, NE 68198, USA. ${ }^{6}$ Department of Pediatrics, University of Nebraska Medical Center, Omaha, NE 68198, USA.

Received: 4 October 2021 Accepted: 1 December 2021

Published online: 18 December 2021

\section{References}

1. Bahmad HF, Poppiti RJ (2020) Medulloblastoma cancer stem cells: molecular signatures and therapeutic targets. J Clin Pathol 73:243-249. https://doi.org/10.1136/jclinpath-2019-206246

2. Bartel DP (2009) MicroRNAs: target recognition and regulatory functions Cell 136:215-233. https://doi.org/10.1016/j.cell.2009.01.002

3. Cavalli FMG, Remke M, Rampasek L, Peacock J, Shih DJH, Luu B, Garzia L, Torchia J, Nor C, Morrissy AS et al (2017) Intertumoral heterogeneity within medulloblastoma subgroups. Cancer Cell 31(737-754):e736. https://doi.org/10.1016/j.ccell.2017.05.005

4. Chen EY, Tan CM, Kou Y, Duan Q, Wang Z, Meirelles GV, Clark NR, Ma'ayan A (2013) Enrichr: interactive and collaborative HTML5 gene list enrichment analysis tool. BMC Bioinform 14:128. https://doi.org/10.1186/ 1471-2105-14-128

5. Chen JQ, Ou YL, Huang ZP, Hong YG, Tao YP, Wang ZG, Ni JS, Hao LQ, Lin H (2019) MicroRNA-212-3p inhibits the proliferation and invasion of human hepatocellular carcinoma cells by suppressing CTGF expression. Sci Rep 9:9820. https://doi.org/10.1038/s41598-019-46088-w

6. Cogen PH, Daneshvar L, Metzger AK, Duyk G, Edwards MS, Sheffield VC (1992) Involvement of multiple chromosome 17p loci in medulloblastoma tumorigenesis. Am J Hum Genet 50:584-589

7. Cvekl A Jr, Zavadil J, Birshtein BK, Grotzer MA, Cvekl A (2004) Analysis of transcripts from 17p13.3 in medulloblastoma suggests ROX/MNT as a potential tumour suppressor gene. Eur J Cancer (Oxford, Engl) 40:2525-2532. https://doi.org/10.1016/j.ejca.2004.08.005

8. Denny SK, Yang D, Chuang CH, Brady JJ, Lim JS, Gruner BM, Chiou SH, Schep AN, Baral J, Hamard C et al (2016) Nfib promotes metastasis through a widespread increase in chromatin accessibility. Cell 166:328342. https://doi.org/10.1016/j.cell.2016.05.052

9. Drusco A (2015) A set of differentially expressed cerebro-spinal fluid (CSF) miRNAs can diagnose CNS malignancies

10. Dubuc AM, Remke M, Korshunov A, Northcott PA, Zhan SH, Mendez-Lago M, Kool M, Jones DT, Unterberger A, Morrissy AS et al (2013) Aberrant patterns of $\mathrm{H} 3 \mathrm{~K} 4$ and $\mathrm{H} 3 \mathrm{~K} 27$ histone lysine methylation occur across subgroups in medulloblastoma. Acta Neuropathol 125:373-384. https:// doi.org/10.1007/s00401-012-1070-9

11. Ecker J, Oehme I, Mazitschek R, Korshunov A, Kool M, Hielscher T, Kiss J, Selt F, Konrad C, Lodrini M et al (2015) Targeting class I histone deacetylase 2 in MYC amplified group 3 medulloblastoma. Acta Neuropathol Commun 3:22. https://doi.org/10.1186/s40478-015-0201-7

12. Ecker J, Thatikonda V, Sigismondo G, Selt F, Valinciute G, Oehme I, Muller C, Buhl JL, Ridinger J, Usta D et al (2021) Reduced chromatin binding of MYC is a key effect of HDAC inhibition in MYC amplified medulloblastoma. Neuro Oncol 23:226-239. https://doi.org/10.1093/neuonc/noaa1 91

13. Fane ME, Chhabra Y, Hollingsworth DEJ, Simmons JL, Spoerri L, Oh TG, Chauhan J, Chin T, Harris L, Harvey TJ et al (2017) NFIB mediates BRN2 driven melanoma cell migration and invasion through regulation of $\mathrm{EZH} 2$ and MITF. EBioMedicine 16:63-75. https://doi.org/10.1016/j.ebiom.2017. 01.013

14. Farrell AS, Sears RC (2014) MYC degradation. Cold Spring Harb Perspect Med. https://doi.org/10.1101/cshperspect.a014365

15. Garg N, Bakhshinyan D, Venugopal C, Mahendram S, Rosa DA, Vijayakumar T, Manoranjan B, Hallett R, McFarlane N, Delaney KH et al (2017) CD133(+) brain tumor-initiating cells are dependent on STAT3 signaling to drive medulloblastoma recurrence. Oncogene 36:606-617. https://doi. org/10.1038/onc.2016.235

16. Gronostajski RM (2000) Roles of the NFI/CTF gene family in transcription and development. Gene 249:31-45. https://doi.org/10.1016/s03781119(00)00140-2

17. Hale ML, Thapa I, Ghersi D (2019) FunSet: an open-source software and web server for performing and displaying Gene Ontology enrichment analysis. BMC Bioinform 20:359. https://doi.org/10.1186/ s12859-019-2960-9

18. Hatakeyama H, Cheng H, Wirth P, Counsell A, Marcrom SR, Wood CB, Pohlmann PR, Gilbert J, Murphy B, Yarbrough WG et al (2010) Regulation of heparin-binding EGF-like growth factor by miR-212 and acquired cetuximab-resistance in head and neck squamous cell carcinoma. PLoS ONE 5:e12702. https://doi.org/10.1371/journal.pone.0012702

19. Incoronato M, Urso L, Portela A, Laukkanen MO, Soini Y, Quintavalle C, Keller S, Esteller M, Condorelli G (2011) Epigenetic regulation of miR-212 expression in lung cancer. PLoS ONE 6:e27722. https://doi.org/10.1371/ journal.pone.0027722

20. Jiang C, Wang H, Zhou L, Jiang T, Xu Y, Xia L (2017) MicroRNA-212 inhibits the metastasis of nasopharyngeal carcinoma by targeting SOX4. Oncol Rep 38:82-88. https://doi.org/10.3892/or.2017.5641

21. Jiang X, Chen X, Chen L, Ma Y, Zhou L, Qi Q, Liu Y, Zhang S, Luo J, Zhou X (2015) Upregulation of the miR-212/132 cluster suppresses proliferation of human lung cancer cells. Oncol Rep 33:705-712. https://doi.org/10. 3892/or.2014.3637

22. Jones DT, Northcott PA, Kool M, Pfister SM (2013) The role of chromatin remodeling in medulloblastoma. Brain Pathol 23:193-199. https://doi. org/10.1111/bpa.12019

23. Junttila MR, Westermarck J (2008) Mechanisms of MYC stabilization in human malignancies. Cell Cycle (Georgetown, Tex) 7:592-596. https://doi. org/10.4161/cc.7.5.5492

24. Kanchan RK, Perumal N, Atri P, Chirravuri Venkata R, Thapa I, Klinkebiel DL Donson AM, Perry D, Punsoni M, Talmon GA et al (2020) MiR-1253 exerts tumor-suppressive effects in medulloblastoma via inhibition of CDK6 and CD276 (B7-H3). Brain Pathol (Zurich, Switzerland). https://doi.org/10. 1111/bpa.12829

25. Kool M, Korshunov A, Remke M, Jones DT, Schlanstein M, Northcott PA, Cho YJ, Koster J, Schouten-van Meeteren A, van Vuurden D et al (2012) Molecular subgroups of medulloblastoma: an international meta-analysis of transcriptome, genetic aberrations, and clinical data of WNT, SHH, Group 3, and Group 4 medulloblastomas. Acta Neuropathol 123:473-484. https://doi.org/10.1007/s00401-012-0958-8

26. Kouzarides T (2007) Chromatin modifications and their function. Cell 128:693-705. https://doi.org/10.1016/j.cell.2007.02.005

27. Li X, Zou ZZ, Wen M, Xie YZ, Peng KJ, Luo T, Liu SY, Gu Q, Li JJ, Luo ZY (2020) ZLM-7 inhibits the occurrence and angiogenesis of breast cancer through miR-212-3p/Sp1/NEGFA signal axis. Mol Med 26:109. https://doi. org/10.1186/s10020-020-00239-2

28. Liu H, Li C, Shen C, Yin F, Wang K, Liu Y, Zheng B, Zhang W, Hou X, Chen $X$ et al (2015) MiR-212-3p inhibits glioblastoma cell proliferation by 
targeting SGK3. J Neurooncol 122:431-439. https://doi.org/10.1007/ s11060-015-1736-y

29. Liu RZ, Vo TM, Jain S, Choi WS, Garcia E, Monckton EA, Mackey JR, Godbout R (2019) NFIB promotes cell survival by directly suppressing p21 transcription in TP53-mutated triple-negative breast cancer. J Patho 247:186-198. https://doi.org/10.1002/path.5182

30. Liu Z, Chen J, Yuan W, Ruan H, Shu Y, Ji J, Wu L, Tang Q, Zhou Z, Zhang X et al (2019) Nuclear factor I/B promotes colorectal cancer cell proliferation, epithelial-mesenchymal transition and 5-fluorouracil resistance. Cancer Sci 110:86-98. https://doi.org/10.1111/cas.13833

31. Manoranjan B, Venugopal C, McFarlane N, Doble BW, Dunn SE, Scheinemann K, Singh SK (2013) Medulloblastoma stem cells: modeling tumor heterogeneity. Cancer Lett 338:23-31. https://doi.org/10.1016/j.canlet. 2012.07.010

32. Massimino M, Biassoni V, Gandola L, Garre ML, Gatta G, Giangaspero F, Poggi G, Rutkowski S (2016) Childhood medulloblastoma. Crit Rev Oncol Hematol 105:35-51. https://doi.org/10.1016/j.critrevonc.2016.05.012

33. McDonald JD, Daneshvar L, Willert JR, Matsumura K, Waldman F, Cogen $\mathrm{PH}$ (1994) Physical mapping of chromosome 17p13.3 in the region of a putative tumor suppressor gene important in medulloblastoma. Genomics 23:229-232. https://doi.org/10.1006/geno.1994.1481

34. Meng X, Wu J, Pan C, Wang H, Ying X, Zhou Y, Yu H, Zuo Y, Pan Z, Liu RY et al (2013) Genetic and epigenetic down-regulation of microRNA-212 promotes colorectal tumor metastasis via dysregulation of MnSOD. Gas troenterology 145(426-436):e421-426. https://doi.org/10.1053/j.gastro. 2013.04.004

35. Mollaoglu G, Guthrie MR, Bohm S, Bragelmann J, Can I, Ballieu PM, Marx A, George J, Heinen C, Chalishazar MD et al (2017) MYC drives progression of small cell lung cancer to a variant neuroendocrine subtype with vulnerability to aurora kinase inhibition. Cancer Cell 31:270-285. https:/ doi.org/10.1016/j.ccell.2016.12.005

36. Moran S, Arribas C, Esteller M (2016) Validation of a DNA methylation microarray for 850,000 CpG sites of the human genome enriched in enhancer sequences. Epigenomics 8:389-399. https://doi.org/10.2217/ epi.15.114

37. Northcott PA, Korshunov A, Pfister SM, Taylor MD (2012) The clinical implications of medulloblastoma subgroups. Nat Rev Neurol 8:340-351. https://doi.org/10.1038/nrneurol.2012.78

38. Northcott PA, Korshunov A, Witt H, Hielscher T, Eberhart CG, Mack S, Bouffet E, Clifford SC, Hawkins CE, French P et al (2011) Medulloblastoma comprises four distinct molecular variants. J Clin Oncol Off J Am Soc Clin Oncol 29:1408-1414. https://doi.org/10.1200/JCO.2009.27.4324

39. Ostrom QT, Patil N, Cioffi G, Waite K, Kruchko C, Barnholtz-Sloan JS (2020) CBTRUS statistical report: primary brain and other central nervous system tumors diagnosed in the United States in 2013-2017. Neuro Oncol. https://doi.org/10.1093/neuonc/noaa200

40. Packer RJ, Gajjar A, Vezina G, Rorke-Adams L, Burger PC, Robertson PL, Bayer L, LaFond D, Donahue BR, Marymont MH et al (2006) Phase III study of craniospinal radiation therapy followed by adjuvant chemotherapy for newly diagnosed average-risk medulloblastoma. J Clin Oncol Off J Am Soc Clin Oncol 24:4202-4208. https://doi.org/10.1200/JCO.2006.06.4980

41. Packer RJ, Zhou T, Holmes E, Vezina G, Gajjar A (2013) Survival and secondary tumors in children with medulloblastoma receiving radiotherapy and adjuvant chemotherapy: results of Children's Oncology Group trial A9961. Neuro Oncol 15:97-103. https://doi.org/10.1093/neuonc/nos267

42. Pei Y, Liu KW, Wang J, Garancher A, Tao R, Esparza LA, Maier DL, Udaka YT, Murad N, Morrissy S et al (2016) HDAC and PI3K antagonists cooperate to inhibit growth of MYC-driven medulloblastoma. Cancer Cell 29:311-323. https://doi.org/10.1016/j.ccell.2016.02.011

43. Ramaswamy V, Remke M, Bouffet E, Faria CC, Perreault S, Cho Y-J, Shih DJ Luu B, Dubuc AM, Northcott PA et al (2013) Recurrence patterns across medulloblastoma subgroups: an integrated clinical and molecular analysis. Lancet Oncol 14:1200-1207. https://doi.org/10.1016/s1470-2045(13) 70449-2

44. Roussel MF, Robinson GW (2013) Role of MYC in medulloblastoma. Cold Spring Harb Perspect Med. https://doi.org/10.1101/cshperspect.a014308

45. Schwalbe EC, Lindsey JC, Nakjang S, Crosier S, Smith AJ, Hicks D, Rafiee G, Hill RM, lliasova A, Stone T et al (2017) Novel molecular subgroups for clinical classification and outcome prediction in childhood medulloblastoma: a cohort study. Lancet Oncol 18:958-971. https://doi.org/10.1016/ S1470-2045(17)30243-7
46. Sears R, Nuckolls F, Haura E, Taya Y, Tamai K, Nevins JR (2000) Multiple Ras-dependent phosphorylation pathways regulate Myc protein stability. Genes Dev 14:2501-2514. https://doi.org/10.1101/gad.836800

47. Semenova EA, Kwon MC, Monkhorst K, Song JY, Bhaskaran R, Krijgsman O, Kuilman T, Peters D, Buikhuisen WA, Smit EF et al (2016) Transcription factor NFIB is a driver of small cell lung cancer progression in mice and marks metastatic disease in patients. Cell Rep 16:631-643. https://doi. org/10.1016/j.celrep.2016.06.020

48. Singh SK, Clarke ID, Terasaki M, Bonn VE, Hawkins C, Squire J, Dirks PB (2003) Identification of a cancer stem cell in human brain tumors. Can Res 63:5821-5828

49. Steele-Perkins G, Plachez C, Butz KG, Yang G, Bachurski CJ, Kinsman SL, Litwack ED, Richards L, Gronostajski RM (2005) The transcription factor gene Nfib is essential for both lung maturation and brain development. Mol Cell Biol 25:685-698. https://doi.org/10.1128/MCB.25.2.685-698.2005

50. Vanner RJ, Remke M, Gallo M, Selvadurai HJ, Coutinho F, Lee L, Kushida M, Head R, Morrissy S, Zhu X et al (2014) Quiescent sox2(+) cells drive hierarchical growth and relapse in sonic hedgehog subgroup medulloblastoma. Cancer Cell 26:33-47. https://doi.org/10.1016/j.ccr.2014.05.005

51. Waha A, Waha A, Koch A, Meyer-Puttlitz B, Weggen S, Sorensen N, Tonn JC, Albrecht S, Goodyer CG, Berthold F et al (2003) Epigenetic silencing of the HIC-1 gene in human medulloblastomas. J Neuropathol Exp Neurol 62:1192-1201. https://doi.org/10.1093/inen/62.11.1192

52. Weishaupt $H$, Johansson $P$, Sundstrom A, Lubovac-Pilav Z, Olsson B, Nelander S, Swartling FJ (2019) Batch-normalization of cerebellar and medulloblastoma gene expression datasets utilizing empirically defined negative control genes. Bioinformatics 35:3357-3364. https://doi.org/10 1093/bioinformatics/btz066

53. Wu C, Zhu X, Liu W, Ruan T, Wan W, Tao K (2018) NFIB promotes cell growth, aggressiveness, metastasis and EMT of gastric cancer through the Akt/Stat3 signaling pathway. Oncol Rep 40:1565-1573. https://doi. org/10.3892/or.2018.6574

54. Wu N, Jia D, Ibrahim AH, Bachurski CJ, Gronostajski RM, MacPherson D (2016) NFIB overexpression cooperates with Rb/p53 deletion to promote small cell lung cancer. Oncotarget 7:57514-57524. https://doi.org/10. 18632/oncotarget.11583

55. Xu L, Wang F, Xu XF, Mo WH, Xia YJ, Wan R, Wang XP, Guo CY (2011) Downregulation of miR-212 expression by DNA hypermethylation in human gastric cancer cells. Med Oncol 28(Suppl 1):S189-196. https://doi.org/10. 1007/s12032-010-9691-0

56. Zhou Y, Ji Z, Yan W, Zhou Z, Li H (2017) The biological functions and mechanism of miR212 in prostate cancer proliferation, migration and invasion via targeting Engrailed-2. Oncol Rep 38:1411-1419. https://doi. org/10.3892/or.2017.5805

\section{Publisher's Note}

Springer Nature remains neutral with regard to jurisdictional claims in published maps and institutional affiliations.

Ready to submit your research? Choose BMC and benefit from:

- fast, convenient online submission

- thorough peer review by experienced researchers in your field

- rapid publication on acceptance

- support for research data, including large and complex data types

- gold Open Access which fosters wider collaboration and increased citations

- maximum visibility for your research: over 100M website views per year

At $\mathrm{BMC}$, research is always in progress.

Learn more biomedcentral.com/submissions 